TI 2013-178/II

Tinbergen Institute Discussion Paper

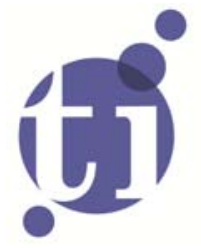

\title{
Legal Principles in Antitrust Enforcement
}

\author{
Harold Houba'
}

Evgenia Motchenkoval

Quan Wen²

1 Faculty of Economics and Business Administration, VU University Amsterdam, and Tinbergen Institute;

2 University of Washington, United States of America. 
Tinbergen Institute is the graduate school and research institute in economics of Erasmus University Rotterdam, the University of Amsterdam and VU University Amsterdam.

More TI discussion papers can be downloaded at http://www.tinbergen.nl

Tinbergen Institute has two locations:

Tinbergen Institute Amsterdam

Gustav Mahlerplein 117

1082 MS Amsterdam

The Netherlands

Tel.: +31(0)205251600

Tinbergen Institute Rotterdam

Burg. Oudlaan 50

3062 PA Rotterdam

The Netherlands

Tel.: +31(0)10 4088900

Fax: $+31(0) 104089031$

Duisenberg school of finance is a collaboration of the Dutch financial sector and universities, with the ambition to support innovative research and offer top quality academic education in core areas of finance.

DSF research papers can be downloaded at: http://www.dsf.nl/

Duisenberg school of finance

Gustav Mahlerplein 117

1082 MS Amsterdam

The Netherlands

Tel.: +31(0)20 5258579 


\title{
Legal Principles in Antitrust Enforcement*
}

\author{
Harold Houba ${ }^{\dagger}$ \\ VU University Amsterdam \\ and Tinbergen Institute \\ Evgenia Motchenkova ${ }^{\ddagger}$ \\ VU University Amsterdam \\ TI and TILEC \\ Quan Wen ${ }^{\S}$ \\ University of Washington \\ First version: November 2011 \\ Revised version: August 2013
}

\begin{abstract}
We study antitrust enforcement that channels price-fixing incentives through setting fines and allocating resources to detection activities. Antitrust fines obey four legal principles: punishments should fit the crime, proportionality, bankruptcy considerations, and minimum fines. Bankruptcy considerations limit maximum fines, ensure abnormal cartel profits and impose a challenge for optimal antitrust enforcement. We integrate the mentioned legal principles into an infinitely-repeated oligopoly model. We derive the optimal level of detection activities and the optimal fine schedule that achieves maximal social welfare under these legal principles. The optimal fine schedule remains below the maximum fine and induces collusion on a lower price by making it more attractive than collusion on higher prices. For a range of low cartel prices, the fine is set to the legal minimum. Raising minimum fines will enable the cartel to raise its price and is better avoided. Our analysis and results relate to the marginal deterrence literature.
\end{abstract}

JEL Classification: L4 Antitrust Policy, K21 Antitrust Law, D43 Oligopoly and Other Forms of Market Imperfection, C73 Stochastic and Dynamic Games; Repeated Games

Keywords: Antitrust enforcement, Antitrust Law, Cartel, Oligopoly, Repeated game

${ }^{*}$ We would like to thank Joseph Harrington, Jose Luis Moraga-Gonzalez, Massimo Motta, Michele Polo, Daniel Rubinfeld, Giancarlo Spagnolo, Yannis Katsoulacos, David Ulph and the participants of ALEA (2012), EARIE (2012), and CRESSE (2012) conferences for stimulating discussions and valuable comments.

${ }^{\dagger}$ Department of Econometrics, VU University Amsterdam, De Boelelaan 1105, 1081 HV Amsterdam, Netherlands. Email: hhouba@feweb.vu.nl.

${ }^{\ddagger}$ Department of Economics, VU University Amsterdam, De Boelelaan 1105, 1081 HV Amsterdam, Netherlands. Email: emotchenkova@feweb.vu.nl.

${ }^{\S}$ Department of Economics, University of Washington, Box 353330, Seattle, WA 98195-3330 U.S.A. Email: wenq2@uw.edu. 


\section{Introduction}

The modern economic theory of law enforcement stems from Becker's (1968) seminal paper. The key message is that the implementation of legal rules changes the economic incentives for illegal practices and the main concern is how society should channel incentives to arrive at an efficient deterrence of such practices. This requires deterring crime only when it is efficient to do so and implementing enforcement in the most cost effective way. Antitrust regulation to deter cartels incorporates the issue of sustainable concerted illegal activities by several offenders. ${ }^{1}$ Most of the current literature, however, is rather silent on how to integrate legal principles into the economic analysis. ${ }^{2}$ Such principles reflect society's moral values about justice and what legal rules are feasible. Legal principles may conflict with the economic principle of efficiency, which makes deterrence less effective. The central aim of this paper is to reconcile legal principles and the economic theory of law enforcement by integrating such principles into a model where one can channel incentives to arrive at the maximal feasible deterrence of illegal concerted activities obeying legal principles.

Becker's original analysis suggests a simple rule: Deter crime only when the harm it causes is greater than the benefit accruing to the offender, and to do it by setting the fine and the probability of conviction so that the expected penalty just equals the offender's benefit. ${ }^{3}$ As this theory takes the view that increasing the rate of law enforcement entails positive social costs, while fines are socially costless, the optimal law enforcement for cartels dictates to set fines to the maximum level in order to save on inspection costs. An adaptation of this rule to antitrust law enforcement is provided by Landes (1983). In the case of cartels, benefit consists of the additional collusive profits plus any cost saving and quality improvement the coordinated practice may generate, net of any cost of enforcement, while harm consists of the consumer surplus transferred to firms in the form of collusive profits plus the utility of

\footnotetext{
${ }^{1}$ See, for example, Harrington (2004, 2005).

${ }^{2}$ Notable exceptions include Buccirossi and Spagnolo (2007) or Cooter and Ulen (2007).

${ }^{3}$ Risk aversion and legal errors could reduce the optimal fine, see e.g. Garoupa (1997, 2001), Polinsky and Shavell (1984, 1991, 1992).
} 
the foregone consumption due to the higher price, i.e., the deadweight loss. It has been argued by many researchers, such as Werden and Simon (1987) and Buccirossi and Spagnolo (2007), that the cartel's benefit from price-fixing is smaller than the harm it causes and that there are no such collusive infringements that may enhance social welfare. Hence, according to this simple rule, the efficient expected fine should be set at the lowest level that deters all possible cartels or all possible collusive prices and to set fines to the maximum available level in order to save on inspection costs.

Buccirossi and Spagnolo (2007) argue that this simple policy prescription is too much in contrast with current practices of antitrust law enforcement in both the US and the EU. First, the EU legislation explicitly sets restrictive ceilings to the maximum applicable fine due to bankruptcy considerations. ${ }^{4}$ Second, an important legal principle is that punishments should be based on the gravity of the offense in order to reflect society's harm and illegal gains. For antitrust, the legislation attempts to relate the fine to a rough measure of gravity that is approximated by the cartel's illegal gains in the US and by the cartel overcharge in the EU. These gravity measures aim to capture the consequences of cartel behavior for the colluding firms and their victims. Third, an equally important legal principle is the principle of proportionality; the regulator should not take any action that exceeds the one which is just necessary to achieve the objective. ${ }^{5}$ In terms of the fine structures, this principle implies that the fine should not be in excess of the lowest fine that suffices to prevent criminal activities.

Ceilings on antitrust fines have been analyzed by Bos and Schinkel (2006), Buccirossi and Spagnolo (2007), Wils (2007), Harrington (2010), or Katsoulacos and Ulph (2013). They argue that the ceilings on antitrust fines in both the US and the EU are insufficient to deter cartels for realistic levels of detection efforts. The ceiling makes antitrust policies either completely ineffective, such that the cartel can sustain all prices including the monopoly

\footnotetext{
${ }^{4}$ See also e.g. Bos and Schinkel (2006), Bageri et al. (2012), or Fabra and Motta (2013). The problem of the insufficient legal ceilings on antitrust fines in the EU raised in the above mentioned papers will be discussed in more details in sections 2 and 4 .

${ }^{5}$ Similar interpretation of this rule can be found in e.g. Burca (1993), Usher (1998), Jacobs (1999), Tridimas (2006), Sullivan and Frase (2008), Fish (2008), or Sauter (2013).
} 
price, or at best partially effective but in such a way that only low prices are deterred, but the high prices are still sustainable by the cartel. This raises the issue whether such negative result is inevitable in the presence of legal ceilings on fines.

One of our main contributions is to revise previous policy prescriptions for an extension of the model in Buccirossi and Spagnolo (2007) in which all relevant legal principles are accounted for. In our model, the price is a continuous variable that is set strategically by the cartel to maximize its profit given antitrust enforcement that consists of a pair of instruments: prosecution and detection effort and a fine schedule. Antitrust enforcement is also endogenous and it is set strategically so that social welfare is maximized while the fine schedule obeys the legal principles. Technically speaking, the fine structure is a function of the cartel price and other parameters of the model. Optimizing over the space of all feasible fine schedules is a challenging mathematical problem that we solve by sound economic reasoning alone without the need of complicated mathematics. We first determine the structure of the optimal fine schedule for the setting where the resources devoted to detection and prosecution are exogenously given. Then, we extend this reasoning to the case in which antitrust enforcement consists of prosecution and detection efforts and a fine schedule that are both endogenous. We show that the structure of the optimal fine schedule under exogenous effort also emerges when the effort level is endogenized.

Another major result is that even in the presence of legal ceilings, it is possible to design a more effective fine structure that is welfare improving when compared to the policy prescriptions currently available in the literature. We demonstrate this by constructing the most effective optimal fine schedule that satisfies four legal principles. This fine schedule induces the lowest cartel price that is optimal for the cartel and, hence, reduces the deadweight loss to its lowest achievable level. This improvement is achieved by making collusion on lower prices more attractive than collusion on higher prices. More precisely, we characterize the maximal threshold price level for which all cartel prices below this price level will never be prosecuted. We will identify this threshold as the minimal cartel price that 
antitrust enforcement can achieve. Alternatively, the problem we analyze can be viewed as an implementation problem through antitrust enforcement rather than regulation: ${ }^{6}$ Which fine schedule implements the lowest achievable cartel price given current legal rules? We aim to derive the optimal fine schedule and effort levels that allow to minimize possible welfare distortions given that the current sentencing guidelines set restrictive (either explicit or implicit) restrictions on fines, such as above mentioned legal rules and upper bounds. One of the striking results is that instead of increasing fines to the legal upper bound, which has a lot of adverse effects, antitrust agencies could implement a "minmax" fine schedule that induces a better outcome with lower fine level.

The optimal fine schedule we derive is related to the literature on marginal deterrence by Stigler (1971), Shavell (1992), Wilde (1992), and Mookherjee and Png (1994). ${ }^{7}$ Shavell (1992) and Wilde (1992) analyze individual offenders and only two illegal acts under a constant legal upper bound. They derive that the fine for the most-harmful act should be set equal to the legal upper bound, while the least-harmful act should receive a lower punishment that induces offenders to choose it. Mookherjee and Png (1994) generalize the analysis of Shavell (1992) and Wilde (1992) to a setting, in which the level of illegal activity is a continuous variable, and obtain that the range of less-harmful acts should be legalized. Our paper arrives at similar results in a different setting, which allow to accommodate and analyze the implications of the specific legal principles imposed in antitrust enforcement. ${ }^{8}$ Furthermore, we extend the analysis in Mookherjee and Png (1994) by taking into account the intertemporal aspects associated with cartel stability and incorporating the additional condition for sustainability of group violations by cartel members.

\footnotetext{
${ }^{6}$ For example, regulation could be imposing an ex-ante price cap such as the competitive price. In the OECD countries, however, regulating all markets by price-caps is, probably, not feasible and may be regarded as unwanted and governments rely on ex-post antitrust enforcement instead.

${ }^{7}$ Besanko and Spulber (1989) and Souam (2001) investigated optimal antitrust policies under asymmetric information. In a number of cases they also find that it is optimal to tolerate some degree of collusion and allow low cost industries to engage in price-fixing. The rational for their results is, obviously, different.

${ }^{8}$ Moreover, we extend the analysis in above mentioned marginal deterrence papers under weaker assumptions in the context of antitrust enforcement with group violations instead of multiple individual actions, including a non-constant ceiling instead of a constant ceiling.
} 
To summarize the paper contributes to the law and economics literature at two interrelated levels, the theoretical and policy level. Our first theoretical contribution shows that it may be socially optimal, even abstracting from enforcement costs, that "low-harm" concerted crimes should not be penalized. Our second theoretical contribution is incorporating and analyzing the effects of legal principles, modelled as constraints, in an advanced gametheoretic model. At the policy level, we show that imposing legal principles allows to obtain sharp and novel policy implications in the context of antitrust enforcement. We provide an alternative solution by modernizing methodologies for implementing penalty policies, which prove to be more effective than simply raising fines to the available legal upper bound for all types of offences. We show that even in the presence of insufficient legal upper bounds the effectiveness of deterrence can still be improved by reducing fines for mild offences as our optimal fine schedule prescribes. The resulting two-part structure of the optimal fine schedule can be employed by antitrust agencies after calibrating it with industry specific parameters.

The rest of this paper is organized as follows. Section 2 discusses the legal principles and how we implement them. Section 3 outlines the model. The optimal fine schedule is derived in Section 4. Section 5 analyzes the setting with endogenous detection effort and confirms the optimal fine structure derived in Section 4. Section 6 provides concluding remarks.

\section{Legal Principles of Antitrust}

Current legislation in the US and EU restricts fines based on legal and economical principles such as punishments should fit the crime, proportionality, bankruptcy considerations, and minimum fines. In this section, we discuss these four principles and how to incorporate them into our analysis.

Punishments Fit the Crime: Antitrust guidelines in the US and EU are founded on the legal principle that punishment should fit the crime, see DOJ (2010) and EC (2006). In practice, this principle translates into higher fines for higher-gravity offenses. Generally 
speaking, the gravity of an offence is related to both the harm caused by the offense and the cartel's illegal gains. In the US, the gravity is measured by the cartel's illegal gains, while in the $\mathrm{EU}$, it is approximated by the cartel overcharge.

Principle of Proportionality: An important principle of current EU legislation is the principle of proportionality that states that regulators should not take any action that exceeds the one which is just sufficient to achieve the same outcome, see e.g. Burca (1993), Usher (1998), Jacobs (1999), Tridimas (2006), Sullivan and Frase (2008), Fish (2008), or Sauter (2013). ${ }^{9}$ Interpreting this principle in terms of the fine structure, it requires that the fine should not be more than the lowest possible fine that would induce the same market outcome, i.e., the least restrictive means (LRM) test. If fines are considered to be socially costless, there is no reason to adopt this principle. However, excessive fines may amplify the possible negative impact of antitrust enforcement, which can stem from unobservable legal errors. Hence, the rationale for adopting the principle of proportionality is to minimize any potential undesirable impact of the antitrust policy.

Bankruptcy Considerations: Both the EU and the US legislation take into account bankruptcy considerations when imposing fines. Normally, this is implemented by imposing (either explicitly or implicitly) ceilings on fines. These ceilings are justified on the ground that legislators do not want to jeopardize the financial stability of the offending firms. Besides employment considerations, high fines that cause bankruptcy are against the ultimate goal of antitrust law because such high fines would reduce the number of active competitors in the market.

In the EU, fines are limited up to $10 \%$ of overall total annual turnover, see e.g. EC (2006), Bos and Schinkel (2006), Bageri et al. (2012), or Fabra and Motta (2013). Total turnover is indirectly related to the illegal gains or price-markups in the markets corrupted by cartel agreements, because it consists of the total sales over all the product markets in which

\footnotetext{
${ }^{9} \mathrm{~A}$ detailed overview of the history and application of the principle of proportionality in the EU and the US is provided in Appendix A.
} 
the company operates, while only some of these markets may be involved in the collusive agreement. There is no formal legal upper bound on the antitrust fines in the US. However, in many cases, such as e.g. the UCAR 1993 case, fines were reduced due to firms' inability to pay. In such a setting, the existence of an implicit ceiling on fines, which is determined by the firms' limited liability, can be argued.

Minimum Fines: According to the current sentencing guidelines in the US, the base fine can be zero for some mild offenses, see DOJ (2010). Moreover, rewarding firms that violate antitrust law is not possible according to the current rules both in the US and the EU. This indicates that imposing no or a zero fine has to be regarded as the minimum fine.

Modelling Legal Antitrust Principles: We analyze fines that satisfy the legal principles listed above in an oligopoly model of price competition. Current antitrust legislation relates the fine to a measure of gravity that is approximated by the cartel's illegal gains or by the cartel overcharge. ${ }^{10}$ Because both cartel's illegal gains and overcharge are positively related to the relevant cartel price, we model the fine schedule as a function of cartel price to accommodate the current practice in the US and EU. As in Becker (1968) and Posner (1976), the optimal antitrust enforcement consists of a fine schedule and effort level of inspection and prosecution that maximize the social welfare. In addition, the fine schedule must satisfy the four principles discussed above.

The bankruptcy considerations and the minimum fines impose upper and lower bounds on the fine schedule. The upper bound is a given function of the cartel price in order to capture current guidelines in the US and EU. By doing so, our approach accommodates for the three main interpretations of the current guidelines: a constant upper bound, a percentage of annual overall turnover, and bounds related to the cartel's illegal gains. With

\footnotetext{
${ }^{10}$ The 2006 Guidelines revise those adopted in 1998, with a view to increasing the deterrent effect of fines. Council Regulation 1/2003 (as with Council Regulation 17/62 before it) provides that companies may be fined up to $10 \%$ of their total annual turnover. Within this limit, the revised Guidelines provide that fines may be based on up to $30 \%$ of the company's annual sales to which the infringement relates. In particular, the basic amount of the fine will be related to a proportion of the value of sales, depending on the degree of gravity of the infringement, multiplied by the number of years of infringement.
} 
respect to the minimum fine, the fine schedule is bounded by a legal lower bound in order to capture the feature that rewards are not allowed in the current guidelines in the US and EU.

The principle that punishment should fit the crime implies that a higher cartel price should cause a higher fine. In other words, the fine schedule should be non-decreasing in order to incorporate the possibility that a range of mild offenses are not fined. The legal principle of proportionality requires that the fine should be kept to the minimum that is just necessary to induce the best social outcome within the domain of fine schedules that satisfy the other three principles.

\section{The Model}

Consider an infinitely-repeated oligopoly model with discounting in the presence of antitrust enforcement. Given the probability to be detected and the fine structure, if the firms collude, they will be detected probabilistically and fined according to the fine structure. We study a stationary subgame perfect equilibrium of this repeated game model where the cartel maximizes its present value of the stream of profits under the antitrust policy that satisfies the four legal principles discussed in the previous section.

In every period, $n \geq 2$ firms compete in a symmetric Bertrand oligopoly model. ${ }^{11}$ Let $\pi\left(p_{1}, \ldots, p_{n}\right)$ be a firm's profit under price profile $\left(p_{1}, \ldots, p_{n}\right)$, and denote $\pi(p) \equiv \pi_{i}(p, \ldots, p)$ when the firms collude at price $p$. Let $\pi^{\text {opt }}(p) \equiv \sup _{p^{\prime}} \pi\left(p^{\prime}, p, \ldots, p\right)$ be the least upper bound of a firm's profit from a unilateral deviation against the cartel price $p$. Denote the symmetric Nash equilibrium price and the maximal symmetric collusive price by $p^{N}$ and $p^{M}$, respectively. Assume that $\pi(p)$ and $\pi^{\text {opt }}(p)$ are continuous and strictly increasing in $p \in\left[p^{N}, p^{M}\right]$, and $\pi^{o p t}(p)>\pi(p)$ for all $p \in\left(p^{N}, p^{M}\right]$. Without loss of generality, we normalize this oligopoly model such that $\pi\left(p^{N}\right)=0$ and interpret $\pi(p)$ as the net profit above $\pi\left(p^{N}\right)$.

\footnotetext{
${ }^{11}$ This model includes homogeneous products, heterogeneous products, and spacial price competition Our analysis can be adapted for quantity competition.
} 
Antitrust enforcement consists of the antitrust authority's (AA) effort level to detect and prosecute the cartel and a fine structure. A higher effort of detection/prosecution leads to a higher probability to detect the cartel, but associates with a higher cost. Due to limited resources of the $\mathrm{AA}$, assume that the probability to detect the cartel is given by $\beta \in[0,1]$. Note that $\beta=0$ is equivalent to a situation with no antitrust enforcement. In section 5 , we endogenize the detection probability.

The fine structure is modeled as a function of the cartel price. If the firms are found guilty of sustaining cartel price $p \in\left(p^{N}, p^{M}\right]$, then every firm will have to pay the one-time fine $\xi(p)$, where $p$ is a proxy of the gravity of offence. Here we maintain the specification of Rey (2003) that only misconduct in the current period is prosecuted. The fine schedule $\xi(\cdot)$ is a function of $p$ that obeys the four legal principles discussed in the previous section. It is continuous, nondecreasing, satisfies proportionality, and the legal upper and lower bounds. We interpret $\xi(p)=0$ as no prosecution. ${ }^{12}$ The legal upper bound $\bar{\xi}(\cdot)$ is assumed to be positive, continuous and nondecreasing in $p$.

The legal principle of proportionality requires some explanation. A fine schedule that is limited by an insufficient legal upper bound is ineffective to deter some cartel prices and, hence, the cartel will form. Given $\beta$ and $\xi(\cdot)$, the cartel will choose the optimal cartel price that maximizes the present value of its member's profit with discount factor $\delta \in(0,1)$. The fine schedule $\xi(\cdot)$ satisfies the legal principle of proportionality if there does not exist another fine schedule $\hat{\xi}(\cdot) \leq \xi(\cdot)$ such that $\hat{\xi}(\cdot)$ induces the same optimal cartel price as $\xi(\cdot)$ does. This class of fine schedules accommodates the current practice of fines that are related to the illegal profits, revenues, or cartel overcharge through the gravity of the offence as described in OECD (2002), EC (2006), and DOJ (2010). These practices can be seen as fines that are non-decreasing functions of the cartel price.

\footnotetext{
${ }^{12}$ Mookherjee and Png (1994) also introduce the prosecution rate as an instrument to be set by the AA. In case there are no social costs associated with the level of the fine, they show that the AA always chooses to prosecute with probability one. In our model, such a prosecution rate must also be equal to one whenever the AA sets a positive expected fine and this rate would be undetermined if the AA sets an expected fine of zero. For these reasons, we omit modelling a prosecution rate.
} 
Observe that the static Nash equilibrium price $p^{N}$ is always sustainable by subgame perfect equilibrium for all $\delta \in(0,1)$, which is also the first-best outcome in the model outlined above. We now discuss a stationary subgame perfect equilibria supported by the following modified trigger strategy profile in the presence of antitrust enforcement: The firms collude at price $p>p^{N}$ in the first period and continue to set price $p$ as long as no firm deviates from the cartel price $p$. Any price deviation by some of the firms will lead to the static Nash equilibrium price $p^{N}$ in every period thereafter. The behavior after any deviation reflects a permanent breakdown of trust among the firms, and without trust, the firms will not be able to form a cartel anymore. As in Motta and Polo (2003), here we assume that the cartel will continue every time it is detected and fined. Alternatively, Harrington (2004, 2005) and Houba, Motchenkova, and Wen (2012) consider situations where the cartel will dissolve with either certainty or some probability each time it is detected. Assuming the cartel will reestablish after each time it is detected is consistent with the cartel's profitmaximizing behavior. It is worthwhile to point out that how the cartel behaves after it is detected does not change the qualitative aspect of our analysis and results.

Let $v(p, \xi)$ be the present value of a firm's expected profit from the above strategy profile. It equals the current illegal net profits $\pi(p)$, minus the expected fine $\beta \xi(p)$, plus the expected continuation value $\delta v(p, \xi)$. Solving for $v(p, \xi)$ yields the following profit function for every cartel member:

$$
v(p, \xi)=\frac{\pi(p)-\beta \xi(p)}{1-\delta}
$$

As in Motta and Polo (2003), price-deviating firms will not be prosecuted. ${ }^{13}$ Given the modified trigger strategy profile, the profit of any firm from a unilateral deviation is equal to the short-term net gain $\pi^{o p t}(p)$ in the current period, minus an expected fine of zero (no prosecution), plus the normalized profit from $p^{N}$ forever. The necessary and sufficient

\footnotetext{
${ }^{13}$ Alternative assumptions such as the possibility of prosecuting price-deviating firms would only relax the equilibrium condition for collusion to be sustainable. Hence, our results will not qualitatively change if such alternative assumption were imposed.
} 
condition to support cartel price $p \in\left(p^{N}, p^{M}\right]$ by a subgame perfect equilibrium is

$$
v(p, \xi)=\frac{\pi(p)-\beta \xi(p)}{1-\delta} \geq \pi^{o p t}(p) .
$$

An optimal cartel price maximizes the present value of each firm's expected profit and the set of optimal cartel prices is

$$
P^{C}(\xi)=\arg \max _{p \in\left(p^{N}, p^{M}\right]} v(p, \xi) \quad \text { subject to } v(p, \xi) \geq \pi^{o p t}(p)
$$

Observe that a lower cartel price implies a lower deadweight loss, or a higher social welfare. Hence, our objective is to identify the optimal fine schedule that induces the lowest optimal cartel price in the class of fine schedules that satisfy the four legal principles. The design of the optimal fine schedule takes into account the optimal reaction by the cartel to the antitrust enforcement.

\section{The Optimal Fine Schedule}

In this section, we will characterize the optimal fine schedule in the following three steps. First, we identify the profit level the cartel can guarantee to each firm when facing any fine schedule that satisfies the four legal principles. Second, given the legal lower bound of a fine schedule, we derive the lowest possible cartel price at which each firm receives the minmax profit we identified in step one. Lastly, we provide a fine schedule that satisfies the four legal principles and induces the minimal cartel price. We will show that this fine schedule is the lowest fine schedule that also induces this minimal cartel price, and it is the optimal fine schedule. We conclude this section by relating our results to the literature on marginal deterrence.

\subsection{The Minmax Cartel Profit}

The rationale of the Beckerian tradition is that the expected loss of being punished should outweigh the expected benefit of committing the crime, see e.g., Becker (1968) or Posner (1976). The condition of marginal deterrence in Stigler (1970) states that the marginal 
benefit of an illegal activity should be equal to the marginal expected fine to deter such an activity. In its most elementary form, this suggests $\beta \xi(p) \geq \pi(p)$ in our antitrust enforcement problem, where the Beckerian tradition and Stigler's marginal deterrence are equivalent. If the AA were able to set the fine high enough, such as $\xi(p)>\frac{1}{\beta} \pi(p)$ for all $p>p^{N}$, it would be unprofitable for the firms to collude because equilibrium condition (2) fails for all $p>p^{N}$.

Bos and Schinkel (2006), Buccirossi and Spagnolo (2007), Wils (2007), and Harrington (2010), ${ }^{14}$ however, point out that the current inspection efforts and the existing upper bounds on fines, at least in the EU and several OECD countries, are insufficient to deter all cartels. ${ }^{15}$ This might be a consequence of bankruptcy considerations that impose, say, $\bar{\xi}(p) \leq \pi(p)$ or $\bar{\xi}(p) \leq \frac{\pi(p)}{1-\delta} \cdot{ }^{16}$ Then, no matter what the legal upper bound $\bar{\xi}$ on fines may be, for a low enough detection probability $\beta$ the upper bound cannot prevent the cartel from colluding at a price above $p^{N} \cdot{ }^{17}$ This suggests that the existing legal upper bound $\bar{\xi}(p)$ and levels of detection probability $\beta$ not only fail the Beckerian structure but also are not high enough to deter cartel formation so that some collusive prices can still be sustained, i.e. the following inequality holds

$$
v(p, \bar{\xi}) \geq \pi^{o p t}(p) \Leftrightarrow \bar{\xi}(p) \leq \frac{1}{\beta}\left[\pi(p)-(1-\delta) \pi^{o p t}(p)\right]
$$

for some $p \in\left(p^{N}, p^{M}\right]$. Accordingly, we assume that the exogenous legal upper bound $\bar{\xi}(p)$ satisfies (4), so that any fine schedule $\xi(p)$ bounded by the legal upper bound $\bar{\xi}(p)$ is also insufficient to deter all cartel prices.

Recall that we are searching for the optimal fine schedule that satisfies the four legal principles, including the legal upper bound. For any fine schedule $\xi(p) \leq \bar{\xi}(p)$, observe that

\footnotetext{
${ }^{14}$ Furthermore, Harrington (2010) argues that it may not be possible at all to raise corporate penalties to a level sufficient to deter collusion for realistic detection probabilities.

${ }^{15}$ In a number of related empirical studies, Connor and Lande $(2005,2006,2008,2012)$ also argue that the existing US and EU penalties for cartel violations are too low resulting in high cartel overcharges.

${ }^{16}$ Another reason to impose legal ceilings on fines or to limit the liability of cartel members is that fines may magnify the social costs of legal errors. In such setting, the imposition of legal upper bounds can be justified even if they restrict the ability of antitrust enforcement to deter all cartel prices. This topic lies outside the scope of this paper.

${ }^{17}$ In Section 5 , the detection probability $\beta \in[0,1]$ becomes endogenous and there the optimal fine schedule for small detection probabilities also plays a role in determining the socially optimal antitrust policy.
} 
if condition (4) is satisfied at $p>p^{N}$, then

$$
v(p, \xi)=\frac{\pi(p)-\beta \xi(p)}{1-\delta} \geq \frac{\pi(p)-\beta \bar{\xi}(p)}{1-\delta}=v(p, \bar{\xi}) \geq \pi^{o p t}(p)
$$

which implies that such $p$ can also be sustained as a cartel price when the fine schedule $\xi(p)$ is imposed. Inequality (5) also implies that if the firms set the corresponding optimal cartel price, each cartel member receives no less when facing $\xi(p)$ than when facing the upper legal bound $\bar{\xi}(p)$. In other words, when facing a fine schedule that obeys the legal upper bound, each cartel member should receive at least what it can receive when facing the legal upper bound and setting the corresponding optimal cartel price.

Proposition 1 For all fine schedules $\xi(\cdot) \leq \bar{\xi}(\cdot)$, we have

$$
\max _{p: v(p, \xi) \geq \pi^{o p t}(p)} v(p, \xi) \geq \max _{p: v(p, \bar{\xi}) \geq \pi^{o p t}(p)} v(p, \bar{\xi})
$$

Proof. Take any optimal cartel price when facing the fine schedule $\bar{\xi}(\cdot)$,

$$
p^{C} \in \arg \max _{p} v(p, \bar{\xi}) \quad \text { subject to } v(p, \bar{\xi}) \geq \pi^{o p t}(p)
$$

Because $\xi\left(p^{C}\right) \leq \bar{\xi}\left(p^{C}\right)$, we have $v\left(p^{C}, \xi\right) \geq v\left(p^{C}, \bar{\xi}\right) \geq \pi^{o p t}(p)$, so $p^{C}$ can also be sustained as a cartel price if the fine schedule is $\xi(p)$. Note that the left-hand side of $(6)$ is greater than or equal to $v\left(p^{C}, \xi\right) \geq v\left(p^{C}, \bar{\xi}\right)$, which is the right-hand side of $(6)$.

In fact, the right-hand side of (6) is at least what the cartel can guarantee each member when facing any function that obeys the legal upper bound. It plays an important role in finding the optimal fine schedule. Accordingly, we denote this minmax cartel profit as

$$
\begin{aligned}
v^{*} & =\max _{p} v(p, \bar{\xi}) \quad \text { subject to } v(p, \bar{\xi}) \geq \pi^{o p t}(p) \\
& =\min _{\xi \leq \bar{\xi}} \max _{p} v(p, \xi) \quad \text { subject to } v(p, \xi) \geq \pi^{o p t}(p)
\end{aligned}
$$

Under the legal upper bound $\bar{\xi}(\cdot)$, the condition for sustainable cartel prices requires that $v(\cdot, \bar{\xi}) \geq \pi^{o p t}(\cdot)$. Figure 1 illustrates both $v(\cdot, \bar{\xi})$ and $\pi^{o p t}(\cdot)$, together with the range of 


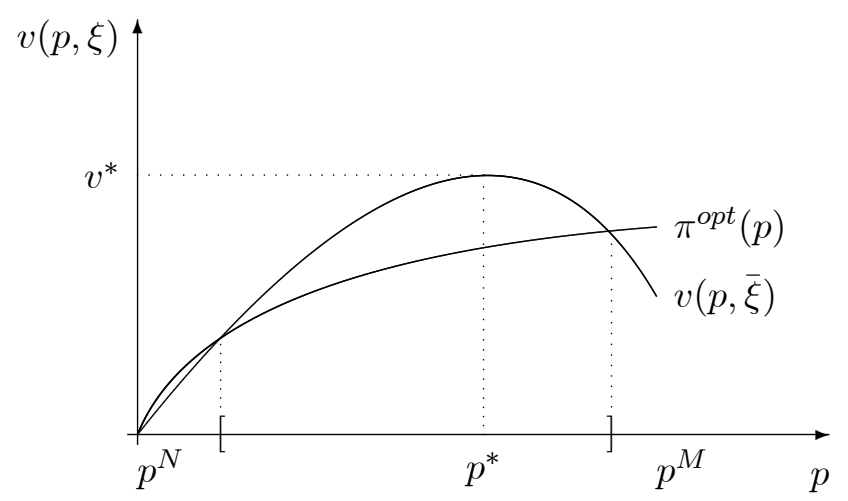

Figure 1: The minmax cartel profit $v^{*}$ and the optimal cartel price $p^{*}$

sustainable cartel prices between the square brackets on the price axis. Under the legal upper bound $\bar{\xi}(\cdot)$, the cartel sets an optimal cartel price $p^{*}$ in this range and each firm obtains $v^{*}$.

The minmax cartel profit $v^{*}$ plays a prominent role in determining the optimal fine schedule. It can be viewed as the cartel's security level or the lowest maximal cartel profit for all fine schedules that are bounded by the legal upper bound. More specifically, for any fine schedule $\xi(\cdot)$ that is bounded by the legal upper bound $\bar{\xi}(\cdot)$, a firm's profit $v(\cdot, \xi)$ is always bounded from below by $v(\cdot, \bar{\xi})$. Because $\pi^{\text {opt }}(\cdot)$ does not depend on the fine schedule, any cartel price under the legal upper bound, such as $p^{C}(\bar{\xi})$, can also be sustained as a cartel price under such a fine schedule $\xi(\cdot)$. Therefore, under fine schedule $\xi(\cdot) \leq \bar{\xi}(\cdot)$, the cartel is able to obtain at least as $v^{*}$ by setting price at $p^{*}$ :

$$
v\left(p^{*}, \xi\right) \geq v\left(p^{*}, \bar{\xi}\right)=v^{*} \geq \pi^{o p t}\left(p^{*}\right)
$$

In general, however, each firm may receive more than $v^{*}$ when facing a fine schedule that is less than the legal upper bound.

\subsection{The Minimal Cartel Price}

Imposing the legal upper bound will certainly induce the minmax cartel profit $v^{*}$ to every firm. However, given that it is impossible to prevent the cartel under the legal upper bound, the objective of antitrust enforcement is not to minimize the cartel profit, but rather to min- 
imize the harm caused by the cartel. Given a fine schedule must also satisfies the three other legal principles, the question is how to minimize the harm caused by the cartel given that each firm must receive a profit that is at least the minmax cartel profit. In this subsection, we identity this achievable minimal cartel price.

Recall the value function (1) and any fine schedule must also be bounded from below by some exogenous legal lower bound, normalized to be zero. For $\xi(p) \geq 0$, we have

$$
v(p, \xi)=\frac{\pi(p)-\beta \xi(p)}{1-\delta} \leq \frac{\pi(p)}{1-\delta} .
$$

Proposition 1 asserts that no matter what fine is imposed, the optimal cartel profit is at least $v^{*}$. Therefore, in order for any $p \in\left(p^{N}, p^{M}\right]$ to be a possible optimal cartel price, it must be the case that

$$
v^{*} \leq v(p, \xi) \leq \frac{\pi(p)}{1-\delta} \Leftrightarrow \pi(p) \geq(1-\delta) v^{*} .
$$

Given the monotonicity of the profit function $\pi(p)$ for $p \in\left(p^{N}, p^{M}\right]$, there is a unique price $\hat{p}=\pi^{-1}\left((1-\delta) v^{*}\right)$ at which (9) holds with equality, where $\pi^{-1}(\cdot)$ is the inverse function of $\pi$ for $p \in\left(p^{N}, p^{M}\right]$. Therefore, given the constraint that $\xi(\cdot) \geq 0$, the cartel must set its price equal to $\hat{p}$ or above in order to ensure each member's profit is at least the minmax cartel profit $v^{*}$. Now we argue that such $\hat{p}$ can be sustained as a cartel price if $\xi(\hat{p})=0$. Observe that

$$
v(\hat{p}, 0)=\frac{\pi(\hat{p})}{1-\delta}=v^{*}=v\left(p^{*}, \bar{\xi}\right)=\frac{\pi\left(p^{*}\right)-\beta \bar{\xi}\left(p^{*}\right)}{1-\delta} \geq \pi^{o p t}\left(p^{*}\right),
$$

where the last inequality is due to (8). Because $\bar{\xi}\left(p^{*}\right) \geq 0$, the monotonicity of $\pi(\cdot)$ implies that $\pi(\hat{p}) \leq \pi\left(p^{*}\right)$, which in turn implies that $\hat{p} \leq p^{*}$. Due to the assumption that $\pi^{\text {opt }}(\cdot)$ is also monotonically increasing, (10) implies that

$$
v(\hat{p}, 0) \geq \pi^{o p t}\left(p^{*}\right) \geq \pi^{o p t}(\hat{p}),
$$

which means that $\hat{p}$ can be sustained as a cartel price. In fact, $\hat{p}$ is the lowest possible optimal cartel price when the firms face any fine schedule that satisfies the four legal principles. For this reason, we call $\hat{p}$ the minimal cartel price. This result is formally presented as 


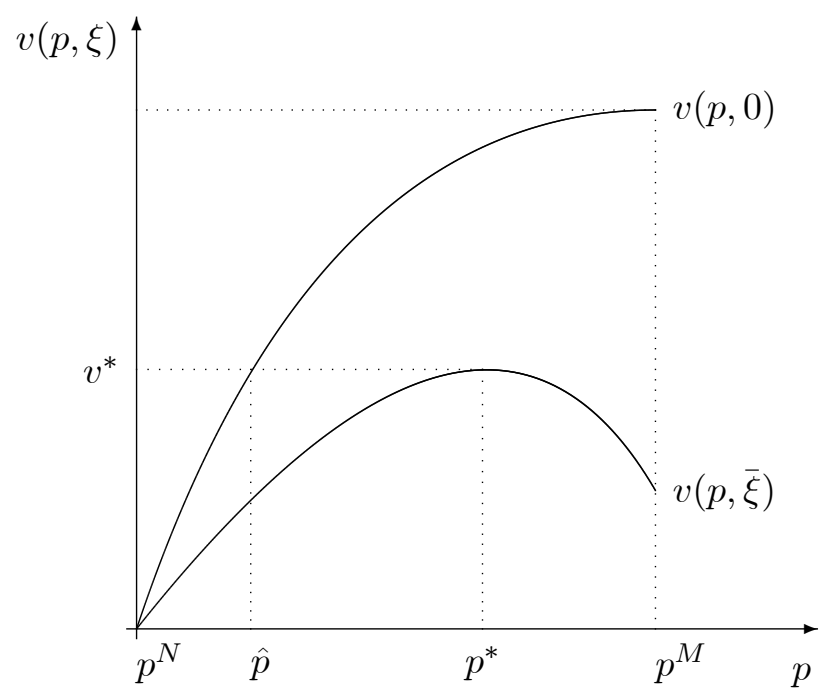

Figure 2: The minimal cartel price $\hat{p}$.

Proposition 2 For any fine schedule $\xi(\cdot)$ that satisfies the four legal principles, any optimal cartel price is bounded from below by the minimal cartel price $\hat{p}=\pi^{-1}\left((1-\delta) v^{*}\right)$.

Built upon Figure 1, Figure 2 illustrates how the minimal cartel price is determined by the minmax cartel profit. Recall that minmax cartel profit $v^{*}$ is the maximal cartel profit when the legal upper bound $\bar{\xi}(\cdot)$ is imposed. Given the monotonicity of profit function $v(p, 0)=\pi(p) /(1-\delta)$, the minimal cartel price is the one at which each firm receives exactly the minmax cartel profit when the legal lower bound 0 is imposed. For simplicity, we choose not to illustrate the equilibrium condition as we have shown that if $\xi(\hat{p})=0$, the minimal cartel price $\hat{p}$ can be sustained as an equilibrium price by the modified trigger strategy profile.

In searching for the optimal fine schedule that satisfies the four legal principles where the legal upper bound is insufficient to deter cartel activity, the objective of antitrust enforcement should shift to minimize the harm caused by the cartel. This translates into minimization of the optimal cartel price in order to take into account the cartel's response to the fine schedule set. Proposition 2 shows that within the class of fine schedules considered, it is impossible to reduce the cartel price below the minimal cartel price. Now the question is 
whether it is feasible to induce this minimal cartel price with a fine schedule that not only satisfies the upper and lower bounds, but also the monotonicity and, more importantly, the proportionality. If such a fine schedule exists and indeed induces the minimal cartel price, it is the optimal fine schedule under the four restrictions imposed by the legal rules and conventions.

\subsection{Characterization of the Optimal Fine Schedule}

We now derive a fine schedule under which the minimal cartel price is an optimal cartel price. As we have argued, such a fine schedule induces the lowest possible optimal cartel price that is the second-best outcome given that the cartel cannot be completely prevented due to the legal upper bound on fine schedules. Hence, the fine schedule we derive is indeed the optimal fine schedule. In doing so, we utilize all four legal principles, namely monotonicity, lower and upper legal bounds, and proportionality.

In order to achieve the minimal cartel price $\hat{p}$, it is necessary that it can be sustained as a cartel price and that each firm receives the minmax cartel profit $v^{*}$. This requires that the fine should be set to 0 when the firms collude at the minimal cartel price $\hat{p}$. Because the fine schedule must satisfy monotonicity and the legal lower bound of 0 , we conclude that $\xi(p)=0$ for all $p \in\left[p^{N}, \hat{p}\right]$. For this range of prices, whether they can be sustained as cartel prices or not, monotonicity and the legal lower bound are binding in determining the optimal fine schedule.

Next consider the price range $\left(\hat{p}, p^{M}\right]$. If the legal upper bound $\bar{\xi}(\cdot)$ were imposed, the cartel would receive at most a profit of $v^{*}$ by selecting a cartel price $p \in\left(\hat{p}, p^{M}\right]$. Given the minmax cartel profit $v^{*}$ from setting the price at the minimal cartel price $\hat{p}$, the necessary and sufficient condition for $\hat{p}$ to be an optimal cartel price is that for all $p \in\left(\hat{p}, p^{M}\right]$

$$
\text { either } v(p, \xi) \leq v^{*} \quad \text { or } \quad v(p, \xi)<\pi^{o p t}(p) \text {. }
$$

Condition (11) asserts that either $p$ can be sustained as a cartel price but each firm does not 
receive more profit than $v^{*}$, or $p$ cannot be sustained at all. Rewriting (11) yields

$$
\text { either } \xi(p) \geq \frac{1}{\beta}\left[\pi(p)-(1-\delta) v^{*}\right] \quad \text { or } \quad \xi(p)>\frac{1}{\beta}\left[\pi(p)-(1-\delta) \pi^{o p t}(p)\right] .
$$

The legal principle of proportionality requires that the fine is just high enough to reduce the cartel profit either to $v^{*}$ for any $p \in\left(\hat{p}, p^{M}\right]$, or to upset the equilibrium condition (2). Moreover, in order to obey this principle we need to identify the minimum of these two right-hand sides. This yields two cases in (12) depending whether $\pi^{\text {opt }}\left(p^{M}\right) \leq v^{*}$ or not.

This distinction can be related to the level of the legal upper bound $\bar{\xi}(\cdot)$. In case the legal upper bound is relatively low, $v^{*}$ is relatively high and we have $\pi^{o p t}\left(p^{M}\right) \leq v^{*}$. The optimal cartel price is then solely driven by the minmax profit level, and breaking cartel sustainability is irrelevant in the determination of the optimal fine schedule, which is reflected by the fact that all cartel prices are sustainable. In the other case, the legal upper bound is relatively high, $v^{*}$ is relatively low and we have $\pi^{o p t}\left(p^{M}\right)>v^{*}$. Then, the sustainability condition also plays a key role in the determination of the optimal fine schedule. We treat the first case in this section, derive the corresponding optimal fine schedule, and utilize it to illustrate our main results, contributions to the literature, and the policy implications. The analysis of the second case has similar policy implications, however, it involves technical complications related to existence of the optimal fine schedule on some intervals of prices. For that reason, we postpone the analysis of this case to Appendix B.

In the remainder of this section, we consider the case of $\pi^{\text {opt }}\left(p^{M}\right) \leq v^{*}$. Due the monotonicity of $\pi^{\text {opt }}(p)$, we have that $\pi^{o p t}(p) \leq v^{*}$ for all $p \in\left[p^{N}, p^{M}\right]$. Consequently, (12) simplifies to $\xi(p) \geq \frac{1}{\beta}\left[\pi(p)-(1-\delta) v^{*}\right]$, where the right-hand side is monotonic, continuous, and obeys both legal bounds. The legal principle of proportionality requires that the fine schedule is just high enough to reduce the cartel profit to $v^{*}$ for any $p \in\left(\hat{p}, p^{M}\right]$ and, therefore, equality must hold. This gives us the optimal fine schedule for $p \in\left[\hat{p}, p^{M}\right]$. Together with the optimal fine schedule for $p \in\left(p^{N}, \hat{p}\right)$, we obtain Proposition 3 . The resulting optimal fine schedule is illustrated in Figure $3 .{ }^{18}$

\footnotetext{
${ }^{18}$ An alternative fine schedule often discussed in the literature (see e.g. Immordino and Polo (2013)) that
} 


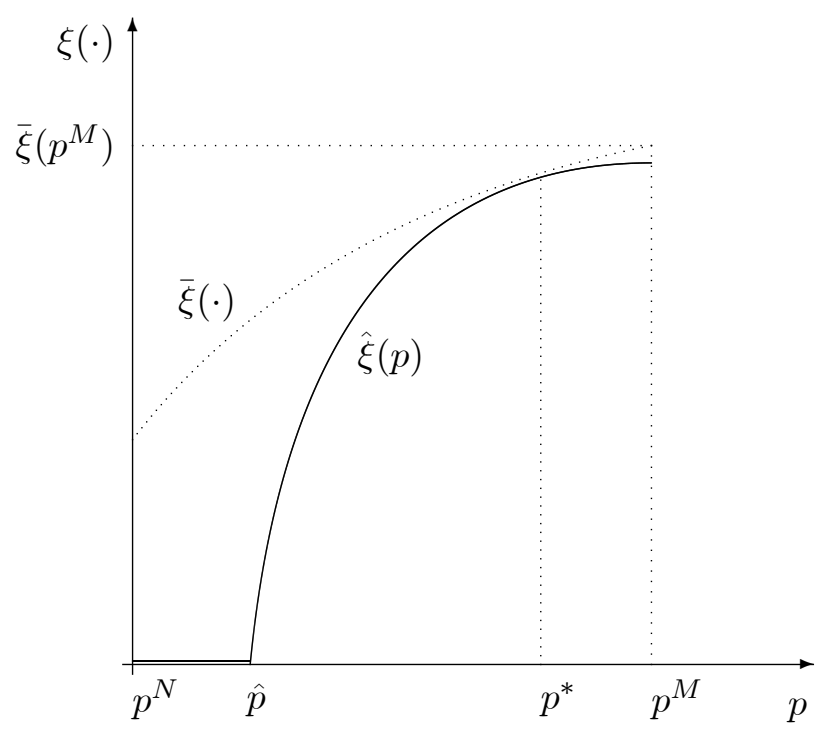

Figure 3: The optimal fine $\hat{\xi}$ (solid) and the legal upper bound $\bar{\xi}$ (dotted).

Proposition 3 When $\pi^{\text {opt }}\left(p^{M}\right) \leq v^{*}$, the optimal fine schedule is given by

$$
\hat{\xi}(p)= \begin{cases}0, & \text { for } p^{N} \leq p \leq \hat{p}, \\ \frac{1}{\beta}\left[\pi(p)-(1-\delta) v^{*}\right], & \text { for } \hat{p}<p \leq p^{M} .\end{cases}
$$

Proof. Because $\pi(\hat{p})=(1-\delta) v^{*}$ by Proposition 2, we have

$$
\lim _{p \rightarrow \hat{p}^{+}} \hat{\xi}(p)=\frac{1}{\beta}\left[\pi(\hat{p})-(1-\delta) v^{*}\right]=0,
$$

hence, $\hat{\xi}(\cdot)$ in (13) is monotonic and continuous. From the construction, we know that such a fine schedule obeys the legal lower and upper bounds. Notice that at $p^{*} \in\left[\hat{p}, p^{M}\right]$, the optimal fine $\hat{\xi}\left(p^{*}\right)$ is equal to the legal upper bound $\bar{\xi}\left(p^{*}\right)$. If $\hat{\xi}(\cdot)$ is imposed, the minimal cartel price $\hat{p}$ is an optimal cartel price because any other price either cannot be sustained as a cartel price or each firm will receive at most the minmax cartel profit.

Recall that in the presence of the legal upper bound the first-best fine schedule is infeasible and antitrust enforcement is insufficient to deter cartel activity. In this case, some cartel prices can be sustained by the cartel and society incurs a deadweight loss. The important However, it only satisfies three legal principles (minimal fines, legal upper bound, and punishment fits the crime) and violates the proportionality principle. 


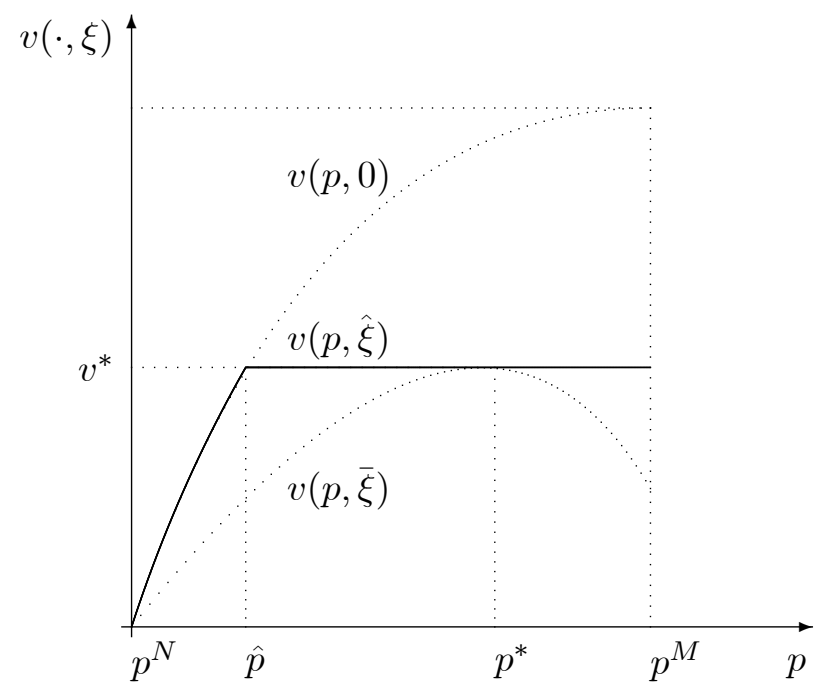

Figure 4: The value function $v(p, \hat{\xi})$ under the optimal fine $\hat{\xi}(p)$.

question is how to keep the deadweight loss minimal given the legal upper bound. According to Proposition 3, the effectiveness of the fine schedule in reducing the optimal cartel price can be maximally improved by adapting fine schedule (13). Figure 3 illustrates that this fine schedule satisfies all four legal principles. Within this class of fine schedules, it is the only one that achieves the smallest attainable optimal cartel price $\hat{p}$. Fine schedule (13) induces the cartel to set $\hat{p}$ as its optimal cartel price. This price lies strictly between the Nash equilibrium price $p^{N}$ and the optimal cartel price $p^{*}$ when the legal upper bound is imposed. This reduces the deadweight loss caused by the cartel.

The maximal reduction of the optimal cartel price is achieved by making all prices in the range between $\hat{p}$ and $p^{M}$ as attractive as $p^{*}$ by reducing the fine below the legal upper bound. Moreover, fine schedule (13) does not punish mild offences of collusion on cartel prices below $\hat{p}$. This result supports the procedure of determination of the base fine in the current US sentencing guidelines, see DOJ (2010), where offences of mild gravity would be assigned a base fine of zero. Note that the value function under $\hat{\xi}(\cdot)$ is given by

$$
v(p, \hat{\xi})= \begin{cases}v(p ; 0), & \text { for } p^{N} \leq p \leq \hat{p} \\ v^{*}, & \text { for } \hat{p}<p \leq p^{M}\end{cases}
$$

which is illustrated in Figure 4. 
Proposition 3 describes the unique SPE outcome supported by the modified trigger strategy profile. Even if some prices above the minimal cartel price $\hat{p}$ can be sustained by the cartel, they are all optimal in the sense that these yield the same profit $v^{*}$ to the cartel. In this equilibrium, the cartel selects the smallest optimal cartel price. There are practical reason why the cartel may prefer to choose this smallest optimal cartel price, such as increase the popularity of the product. Furthermore, if the cartel does not choose this smallest optimal cartel price, the AA would have an incentive to increase the fine slightly higher than $\hat{\xi}(p)$ for any price $p>\hat{p}$, so that the cartel would not choose such price $p>\hat{p}$.

\subsection{Discussion and Relation to the Literature}

In this subsection, we first discuss the robustness of our results and their comparative statics before we relate our results to the literature on marginal deterrence.

\subsubsection{Discussion}

Our results are robust. All qualitative results obtained thus far can also be obtained if the detection probability continuously depends upon the cartel price, which only requires straightforward substitutions in every expression containing the detection probability. A legal lower bound different from 0 requires the following minor modification. Let $\underline{\xi}(p)$ denote the lower bound on the fine schedule. Then, in Figure 2, we replace the curve $v(p, 0)$ by the curve $v(p, \underline{\xi})$ and proceed as before. The modified minimal cartel price solves $\pi(p)-\beta \underline{\xi}(p)=$ $(1-\delta) v^{*}$ and such price is well defined. At the minimal cartel price $\hat{p}$, a legal lower bound above 0 implies that the left-hand side is lower than the right-hand side. In order to restore equality, the first term, $\pi(p)$, has to increase. Hence, a lower bound above 0 increases the minimal cartel price.

In many cases in reality, cartel members and the AA reach pretrial settlements. Assuming such settlements can be captured by a non-decreasing continuous function of the cartel price, one can easily redo our analysis by substituting this settlement function for the legal upper bound. Settlement payments that lie below the legal upper bound reduce the expected 
maximal penalty and, hence, increase the minmax cartel profit and the minimal cartel price. Then, this reduces the effectiveness of antitrust enforcement. Of course, this would ignore the role of defense litigation costs or private damages the cartel members might pay. Both can be modeled through an increase of the legal upper bound and, hence, have the desirable effect of lowering the minimal cartel price. The combined effect of pretrial settlements and defense litigation costs on the minimal cartel price is ambiguous and needs further investigation. One solution is that pretrial settlements might act as an instrument for implementing the optimal fine schedule.

\subsubsection{Relation to the Literature}

For the case of a differentiable profit function, the optimal fine schedule for cartel prices in the range $\left[\hat{p}, p^{M}\right]$ satisfies the condition of marginal deterrence in Stigler (1970) that states that the marginal benefit of the offense should be equal its marginal expected cost. Even in the absence of differentiability, marginal deterrence holds in the following sense. The cartel has no incentive to set a price in the lower range of prices because the present value of profits for each individual firm is strictly increasing in the cartel price on this range due to the zero fine. Also, this present value is less than the security level and, hence, these cartel prices are not optimal.

These insights also relate to the results in Block, Nold, and Sidak (1981) where the design of the optimal (differentiable) fine schedule should be such that the condition of marginal deterrence is achieved on $\left[p^{N}, p^{M}\right]$. Application of their ideas to our setting would imply that

the optimal fine schedule solves the differential equation $\beta \xi^{\prime}(p)=\pi^{\prime}(p)$ for $p \in\left[\hat{p}, p^{M}\right]$ under the additional condition $\xi\left(p^{*}\right)=\bar{\xi}\left(p^{*}\right)$ instead of $\xi\left(p^{M}\right)=\bar{\xi}\left(p^{M}\right)$. In case the differential equation would also be solved for $p \in\left[p^{N}, \hat{p}\right)$, it violates the legal lower bound. Stigler (1970) and Block, Nold, and Sidak (1981) are silent on the issue of sustainability of concerted illegal actions and, hence, our results generalize their analysis to include such concerted actions. In addition, we also extend the analysis to nondifferentiable profit functions and non-constant legal upper bounds. Note that our results directly apply to individual illegal actions in 
antitrust enforcement by ignoring the equilibrium condition in our model. Therefore, both individual and group violations with concerted illegal actions are integrated into one unifying framework.

Before we relate our results to the marginal deterrence studied by Shavell (1992) and Wilde (1992), we first discuss the special case of a constant legal upper bound in our model. Let $\bar{\xi}(p)=\bar{\xi}$ for all $p \in\left[p^{N}, p^{M}\right]$, then profit function $v(p, \bar{\xi})$ becomes strictly increasing on the entire interval $\left[p^{N}, p^{M}\right]$. In characterizing the optimal cartel price $p^{*}$ we must distinguish two cases depending on whether $p^{M}$ can be sustained under the constant legal upper bound $\bar{\xi}$. First, if $p^{M}$ can be sustained as a cartel price, then the monotonicity of $v(p, \bar{\xi})$ implies that the optimal cartel price is $p^{*}=p^{M}$, the minmax cartel profit is $v^{*}=v\left(p^{M}, \bar{\xi}\right)$, and the minimal cartel price is $\hat{p}=\pi^{-1}\left(\pi\left(p^{M}\right)-\beta \bar{\xi}\right)$. The optimal fine schedule imposes the maximal fine $\bar{\xi}$ on the most grave offence $p^{M}$, and all lower prices are fined below the legal upper bound. Second, if $p^{M}$ fails to be a cartel price, then monotonicity of $v(p, \bar{\xi})$ implies that $p^{*}<p^{M}$ is the maximal sustainable cartel price, which is the highest price $p \in\left[p^{N}, p^{M}\right]$ that solves $\pi(p)=(1-\delta) \pi^{o p t}(p)$.

With these observations in mind, we relate our results to the theory of marginal deterrence in Shavell (1992) and Wilde (1992) for individual offenders and two illegal acts under a constant legal upper bound and a common production of detection and conviction. ${ }^{19}$ These references derive that the optimal fine is non-decreasing in the level of harm in order to induce offenders to choose the least harmful act. For antitrust enforcement, illegal acts are represented by a continuum of cartel prices and both the cartel's illegal gains and society's deadweight loss are increasing in the cartel price. Although the optimal fine schedule is nondecreasing in the cartel price, it is directly related to illegal gains rather than to society's harm. As a thought experiment in terms of two illegal acts under a constant fine schedule in our model, consider the case $p \in\left[\hat{p}, p^{*}\right)$ and, for a constant legal upper bound, $p^{*}$ that is

\footnotetext{
${ }^{19}$ The inspection and prosecution efforts of antitrust enforcement are such that a sector must be investigated in order to determine the actual cartel price set. The AA cannot target its activities on specific cartel prices beforehand. Therefore, in terms of Shavell (1992) and Wilde (1992), the production of antitrust enforcement classifies as common production of detection and prosecution.
} 
either the monopoly price or the maximal sustainable cartel price. We have shown that the optimal fine for $p$ is strictly lower than the fine for $p^{*}$. For the remaining case $p \in\left(p^{N}, \hat{p}\right)$ and $p^{*}$, the optimal fine schedule cannot induce the cartel to choose the least harmful act because for such price even the zero fine is not low enough to provide the proper incentives. If that case arises in their model, Shavell (1992) and Wilde (1992) set the fine equal to the legal upper bound and this is in contrast to the principle of proportionality that would set the fine equal to zero. Recall that our results directly apply to individual illegal actions by ignoring the equilibrium condition in our model.

Mookherjee and Png (1994) generalize the analysis of Shavell (1992) and Wilde (1992) to a setting in which the level of illegal activity is a continuous variable, and similar to our results, they obtain that the range of least-harmful acts should be legalized. Our study provides an alternative derivation of these results under weaker assumptions in the context of antitrust enforcement with group violations of concerted illegal actions instead of multiple individual actions and explicit modelling of legal principles, including a non-constant ceiling instead of a constant ceiling. We extend the analysis in Mookherjee and Png (1994) under less restrictive assumptions by taking into account the additional condition for sustainability of group violations by cartel members.

To summarize, our results indicate how to generalize the results in Shavell (1992), Wilde (1992) and Mookherjee and Png (1994) to the case of a non-constant legal upper bound and group violations with multiple concerted illegal actions in the context of antitrust enforcement.

\section{Optimal Antitrust Policy}

The optimal trade-off between resources devoted to detection/prosecution and the severity of punishment has been a major issue within the law and economics literature (see e.g. Polinsky and Shavell $(1979,1992)$ or Garoupa (1997, 2001) for an overview). Our analysis of the previous section focussed on the optimal fine schedule given an exogenous level of 
resources spent on detection. In this section, we endogenize these resources in the form of an endogenous detection probability. This introduces a second policy dimension. We show that, when taking into account the socially optimal trade-off between the two policy dimensions, the structure of the optimal fine schedule identified in Section 4 must be preserved.

We analyze the following straightforward extension of our model. Endogenous antitrust enforcement consists of the pair of instruments $(\beta, \xi)$ : an endogenous detection probability $\beta \in[0,1]$ and an endogenous fine schedule $\xi(p)$ that, as before, is continuous and has to satisfy the four legal principles. In every period, the social costs associated with the resources spent to implement $\beta$ are given by the cost function $c(\beta)$. Assume that $c(\beta)$ is continuous and strictly increasing in $\beta$, and that $c(0)=0$.

Let $w(p, \beta, \xi)$ represent the present value of social welfare associated with antitrust policy characterized by the pair of instruments $(\beta, \xi)$ and cartel price $p \in\left[p^{N}, p^{M}\right]$. It equals the current producer surplus per firm times the number of firms, $n \pi(p)$, plus the current consumer surplus $C S(p),{ }^{20}$ minus the current $\operatorname{cost} c(\beta)$, plus the continuation value $\delta w(p, \beta, \xi) .{ }^{21}$ Solving for $w(p, \beta, \xi)$ yields the social welfare function:

$$
w(p, \beta, \xi)=\frac{n \pi(p)+C S(p)-c(\beta)}{1-\delta}
$$

The objective of antitrust enforcement is to maximize social welfare.

Given endogenous antitrust enforcement $(\beta, \xi)$, the profit function for every cartel member remains given by (1), prices that the cartel can support still obey (2) and the set of optimal cartel prices solves (3). Since both $\beta$ and $\xi$ are endogenous, we include $\beta$ into our notation and write $v(p, \beta, \xi)$ for the present value of a firm's expected profit and $p^{C}(\beta, \xi)$ for an optimal cartel price. Given the objective of antitrust enforcement and the optimal reaction by the cartel, the aim of antitrust enforcement becomes to maximize social welfare

\footnotetext{
${ }^{20}$ Both the profit function and the consumer surplus depend upon the demand function. For explanatory reasons, we forego making this explicit.

${ }^{21}$ For completeness, the expected fine $n \beta \xi(p)$ paid by the $n$ firms cancels against the expected fine $n \beta \xi(p)$ received by the AA, which are both left out.
} 
$w\left(p^{C}(\beta, \xi), \beta, \xi\right)$ over all pairs of instruments $(\beta, \xi)$, where

$$
w\left(p^{C}(\beta, \xi), \beta, \xi\right)=\frac{n \pi\left(p^{C}(\beta, \xi)\right)+C S\left(p^{C}(\beta, \xi)\right)-c(\beta)}{1-\delta} .
$$

Before proceeding with the identification of optimal antitrust enforcement, we will introduce the minimal level of detection the AA has to impose in order to achieve full deterrence that eradicates all cartel prices above the competitive level. This minimal level of detection, denoted as $\bar{\beta}$, is obtained by rewriting (4) and is defined as

$$
\bar{\beta} \equiv \sup _{p \in\left(p^{N}, p^{M}\right]} \frac{1}{\bar{\xi}(p)}\left[\pi(p)-(1-\delta) \pi^{o p t}(p)\right]
$$

Note that, for $\beta<\bar{\beta}$, there exists some subrange of cartel prices in $\left(p^{N}, p^{M}\right]$ that are sustainable and, for $\beta>\bar{\beta}$, all cartel prices above the competitive price $p^{N}$ are deterred, i.e., full deterrence is achievable. ${ }^{22}$ Note also that $\bar{\beta}$ extends the lower bound on the probability of monitoring to deter illegal activities in Mookherjee and Png (1994), i.e., their condition (11). Definition (16) incorporates both the non-constant legal upper bound and, implicitly, the condition for sustainable group violations in the absence of antitrust enforcement, i.e., nonnegativity of the term between square brackets implies $v(p, 0,0) \geq \pi^{\text {opt }}(p)$. In the presence of group violations, the expected fine has to ensure that $v(p, \beta, \xi)$ lies below $\pi^{\text {opt }}(p)$ for all $p \in\left(p^{N}, p^{M}\right]$, i.e., to bridge the gap between $v(p, 0,0)$ and $\pi^{o p t}(p)$, in order to destabilize the cartel. This differs from the unconcerted individual illegal actions in Mookherjee and Png (1994) where $v(p, \beta, \xi)$ has to be lowered to 0 in order to achieve deterrence.

Similar to the discussion in Section 4.3, we identify two cases. The distinction between these cases can, again, be related to the level of the legal upper bound $\bar{\xi}(\cdot)$. In case the legal upper bound is relatively low, $\bar{\beta}$ will be relatively high. Then, we might even have $\bar{\beta}>1$ and all levels of detection are insufficient to achieve full deterrence under the legal upper bound. Only by reconsidering the legal principles and raising the legal upper bound might achieve full deterrence. In the second case, the legal upper bound is relatively high, $\bar{\beta}$ is relatively

\footnotetext{
${ }^{22}$ In Appendix 3, we deal with several technical issues including the issue that $\beta=\bar{\beta}$ may belong to either of these two cases.
} 
low and we might have $\bar{\beta}<1$. Then, society has an option to achieve full deterrence by setting any $\beta \in(\bar{\beta}, 1)$ and the question is whether society prefers to do so, or rather prefers some $\beta<\bar{\beta}$ that only partially deters. In both cases, society faces the traditional trade-off between resources spent on detection and the severity of punishment. Only in the second case, society also faces a trade-off between the more ambitious objective of full deterrence versus the less ambitious objective of partial deterrence.

We treat the case of a relatively-low legal upper bound in this section, characterize the corresponding optimal pair of antitrust instruments, and utilize it to illustrate our main results, contributions to the literature, and the policy implications. The analysis of a relatively-high legal upper bound has similar policy implications, however, it also involves technical complications related to existence of optimal antitrust enforcement. For that reason, we postpone the analysis of this case to Appendix C.

In the remainder of this section, we consider the case of $\bar{\beta}>1$ as representing a relativelylow legal upper bound where full deterrence is out of reach and only partial deterrence is feasible. This set up also seems to be most relevant from the current policy discussion in e.g. Bos and Schinkel (2006), Buccirossi and Spagnolo (2007), or Harrington (2010) who argue that fines both in the US and the EU are insufficient to fully deter cartel activity given realistic levels of detection probabilities.

The following result shows that the structure of the optimal fine schedule identified in the previous section has to be preserved in the setting where both the probability of detection and the fine schedule are endogenous. In order to state it, we write $\hat{p}(\beta)$ for the minimal cartel price $\hat{p}$ as a function of $\beta$ and similar $\hat{\xi}(p, \beta)$ for the optimal fine schedule $\hat{\xi}(p)$.

Proposition 4 Optimal antitrust enforcement $\left(\beta^{*}, \xi^{*}\right)$ has the following features:

(i) $\beta^{*} \in[0,1]$ maximizes per-period social welfare $n \pi(\hat{p}(\beta))+C S(\hat{p}(\beta))-c(\beta)$ in order to implement the minimal cartel price $\hat{p}\left(\beta^{*}\right)$ and

(ii) $\xi^{*}(p)=\hat{\xi}\left(p, \beta^{*}\right)$.

Proof. Note that, by the Theorem of the Maximum, the value function $v^{*}(\beta)$ given by 
(7) is continuous in $\beta$ on $[0,1]$. Then, by Proposition $2, \hat{p}(\beta)=\pi^{-1}\left((1-\delta) v^{*}(\beta)\right)$ is also continuous in $\beta$ on $[0,1]$. Next, for any $p^{C}\left(\beta^{*}, \xi^{*}\right) \in P^{C}\left(\beta^{*}, \xi^{*}\right)$, we have that

$$
\begin{aligned}
w\left(p^{C}\left(\beta^{*}, \xi^{*}\right), \beta^{*}, \xi^{*}\right) & =\sup _{\beta \in[0,1], \xi} w\left(p^{C}(\beta, \xi), \beta, \xi\right), \quad \text { s.t. } \xi \text { satisfies the four legal principles } \\
& =\sup _{\beta \in[0,1]}\left[\sup _{\xi} w\left(p^{C}(\beta, \xi), \beta, \xi\right)\right], \quad \text { s.t. } \xi \ldots \\
& =\sup _{\beta \in[0,1]}\left[\sup _{\xi}\left[\frac{n \pi\left(p^{C}(\beta, \xi)\right)+C S\left(p^{C}(\beta, \xi)\right)}{1-\delta}\right]-\frac{c(\beta)}{1-\delta}\right], \quad \text { s.t. } \xi \ldots \\
& =\max _{\beta \in[0,1]}\left[\frac{n \pi(\hat{p}(\beta))+C S(\hat{p}(\beta))}{1-\delta}-\frac{c(\beta)}{1-\delta}\right] .
\end{aligned}
$$

Continuity of $\hat{p}(\beta)$ on $[0,1]$ guarantees continuity of the objective function in the last line. Hence, an optimal $\beta^{*} \in[0,1]$ exists and the AA implements the minimal cartel price $\hat{p}\left(\beta^{*}\right)$. Our previous results imply that, for $\beta=\beta^{*}$, the fine schedule $\xi^{*}(p)$ given by either (13) or (21) implements $\hat{p}\left(\beta^{*}\right)$.

Proposition 4 implies that optimal antitrust enforcement implements the minimal cartel price $\hat{p}\left(\beta^{*}\right)$, however now this price is associated with the optimal level of detection, $\beta^{*}$. An increase in the detection probability reduces the minimal cartel price and this decreases the deadweight loss. Increasing the detection effort will improve social welfare as long as the benefits in the form of a lower deadweight loss outweigh the costs of directing more of society's resources to detection. Moreover, changes in the detection probability should be accompanied by changes in the optimal fine schedule, otherwise the cartel is able to set a cartel price above the minimal cartel price and extract a larger producer surplus at the expense of the demand side. Therefore, aligning both policy dimensions of antitrust enforcement is of utmost importance.

Equation (15) evaluated at $\hat{p}(\beta)$ allows to investigate the trade-off between the marginal costs and marginal benefits of changes in the detection probability, provided we additionally assume differentiability of all functions. The first-order condition for an interior maximizer $\beta^{*} \in(0,1)$ of $(15)$ is given by

$$
\hat{p}^{\prime}(\beta)\left[n \pi^{\prime}(\hat{p}(\beta))+C S^{\prime}(\hat{p}(\beta))\right]=c^{\prime}(\beta) .
$$


The left-hand side is positive, since the sum of the producer and consumer surpluses is decreasing in $p \in\left[p^{N}, p^{M}\right]$ and $\hat{p}(\beta)$ is non-decreasing in $\beta \in[0,1] .{ }^{23}$ The total marginal benefit depends upon the sensitivity of the minimal cartel price to changes in the detection probability and the standard sensitivity of the deadweight loss to price changes. In the social optimum, the marginal social benefits of detection equal the marginal social costs of this activity. A positive detection probability requires that the marginal social benefits at the no detection effort level exceed the marginal costs of no effort, i.e., $\hat{p}^{\prime}(0)\left[n \pi^{\prime}\left(p^{M}\right)+C S^{\prime}\left(p^{M}\right)\right]>c^{\prime}(0)$ due to $\hat{p}(0)=p^{M}$. A detection probability smaller than 1 requires that the marginal social benefits at the maximum detection effort level are lower than the marginal costs of this effort level, i.e., $\hat{p}^{\prime}(1)\left[n \pi^{\prime}(\hat{p}(1))+C S^{\prime}(\hat{p}(1))\right]<c^{\prime}(1)$.

Finally, Proposition 4 also implies that we may characterize optimal antitrust enforcement in two separate steps: For arbitrary detection probability $\beta \in[0,1]$, characterize the minimal cartel price $\hat{p}(\beta)$ first, and then, solve for the optimal level of detection. The optimal detection probability $\beta^{*} \in[0,1]$ then immediately pins down the optimal fine schedule $\xi^{*}$ as the optimal fine schedule for $\beta=\beta^{*}$ as derived in Section 4.3. Continuity of the minimal optimal cartel price in the detection probability ensures a social-welfare maximizing antitrust enforcement exists. As a final remark, the two-step procedure is mathematically convenient because it circumvents the technically challenging optimization over the space of fine schedules.

\section{Concluding Remarks}

We provide a coherent framework to study the economic consequences of legal principles in crime enforcement with concerted illegal actions by several offenders. Our analysis characterizes optimal antitrust enforcement that consists of a pair of instruments: inspection effort and a fine schedule. The socially optimal antitrust enforcement trades off the standard deadweight loss and the social cost of inspection while taking into account the optimal reaction

\footnotetext{
${ }^{23}$ The minimal cartel price $\hat{p}(\beta)$ is decreasing in $\beta$, because the value function $v^{*}$ given by $(7)$ is decreasing in $\beta$ and, hence, $\hat{p}(\beta)=\pi^{-1}\left((1-\delta) v^{*}\right)$ is also decreasing in $\beta$.
} 
by the cartel. In particular, the optimal fine schedule coincides with the fine schedule that minmaxes the cartel's profit at the optimal inspection effort. This schedule remains below the legal ceiling, except at the cartel price where the minmax cartel profit is achieved under this legal ceiling, and there is a range of low cartel prices for which the fine is set to zero according to the legal lower bound. Hence, the main implication of our analysis is that the antitrust authority should not punish maximally overall, but punish in a smarter manner such that mild offenses are not fined at all. In general, our results call for a subtle reconsideration of the common wisdom in the economics of concerted crime that setting the fine equal to the available legal upper bound always increases the effectiveness of deterrence.

By either adding or substituting other legal principles, one can easily assess the impact of such principles on optimal antitrust enforcement and the enforced cartel price. Therefore, our approach allows to quantify the economic costs of adapting society's legal principles through the differences in society's deadweight losses. For example, increasing maximum penalties by shifting the legal ceiling upwards decreases the cartel's minmax value, and consequently, reduces the cartel price. Although the antitrust authority should shrink the range of low cartel prices where it fines zero and raise the fine schedule elsewhere, the optimal fine schedule remains below the legal ceiling almost everywhere. As another example, imposing minimum fines, a popular call in recent politics, will enable the cartel to set a higher price. Therefore, positive minimum fines reduce social welfare and should never be imposed or, if they are currently implemented, they should be abolished. Our analysis provides a technique to adequately deal with such modifications of legal rules.

Furthermore, in the literature on antitrust enforcement, see Harrington (2010), Buccirossi and Spagnolo (2007), Bos and Schinkel (2006), Bageri et al. (2012), or Katsoulacos and Ulph (2013), it is often argued that corporate antitrust fines are insufficient to successfully deter cartel formation given realistic levels of detection efforts and that the legal upper bounds should be increased. We agree that increasing the legal upper bound is a right trend in 
general. ${ }^{24}$ But we also show that even in the presence of insufficient legal upper bounds the effectiveness of deterrence can still be improved by reducing fines for mild offences as our optimal fine schedule prescribes.

The derived optimal fine schedule can be related to the literature on marginal deterrence by Stigler (1971), Shavell (1992), Wilde (1992) and Mookherjee and Png (1994). Our analysis shows how to generalize the results in these references to the case of a non-constant legal upper bound and both individual and group violations with multiple concerted illegal acts in the context of antitrust enforcement.

Finally, our analysis allows a two step procedure: for arbitrary inspection effort derive the minimal cartel price first, and then, solve for the socially optimal inspection effort. The optimal fine schedule follows from implementing the minimal cartel price at the socially optimal inspection effort. This implies that the structure of the optimal fine schedule derived for exogenous inspection effort must be preserved under endogenous inspection effort. These results indicate that it is worthwhile to align society's detection effort with the structure of the sentencing guidelines, and vise versa, the design of the sentencing guidelines should take into account the restrictions on detection and inspection efforts imposed by limited resources.

\section{Appendix A: The Principle of Proportionality}

In the EU the principle of proportionality has been developed by the Court of Justice of the European Union and requires that freedom of action should not be limited beyond the degree necessary in the public interest. ${ }^{25}$ It appeared for the first time in a judgement of the Court in Fédéchar. ${ }^{26}$ Since the Treaty of Amsterdam of 1997 the principle is incorporated

\footnotetext{
${ }^{24}$ In practice upper bounds on fines are implemented in order to prevent bankruptcy or in order to reduce social costs of legal errors. This is the case in the EU and in many OECD countries as well (see e.g. EC (2006) or OECD (2002)). The focus of our paper is to derive the optimal fine schedule that allows to minimize possible welfare distortions given that the current sentencing guidelines set restrictive (either explicit or implicit) upper bounds on fines.

${ }^{25}$ See e.g. Tridimas (2006) for a more precise definition.

${ }^{26}$ Case 8/55, Fédération charbonnière de Belgique v ECSC High Authority, p. 299.
} 
in the Treaty of the European Union, see Usher (1998). The principle of proportionality is articulated in Article 5 of the Treaty of the European Union. It states that

"Under the principle of proportionality, the content and form of Union action shall not exceed what is necessary to achieve the objectives of the Treaties."

The general implementation of the principle of proportionality by the Court can be described as

"The principle of proportionality requires that action undertaken must be proportionate to its objectives." 27

It is based on the concern to protect individuals against the State and on the assumption that regulatory intervention must be suitable to achieve its aims. ${ }^{28}$ The measure in question must be appropriate and necessary to achieve its objectives. The principle of proportionality can be divided into three tests: a test of suitability, a test of the least restrictive means, and a test of necessity. The test of suitability refers to the relationship between means and the outcome. It implies that the means must be suitable to achieve its objectives. The second test is the least restrictive means test. Following this test it should be established that there are no other less restrictive means available to come to a comparable result.

The proportionality principle also applies in the framework of competition law of the European Commission's enforcement decisions. ${ }^{29}$ In this case, obviously, the powers of the European Commission are under review. Article 7 of the Modernization Regulation includes an explicit proportionality test. ${ }^{30}$ Article 7 directly implies least restrictive means (LRM) testing. In the recent Mastercard (2012) case, the Court further specifies LRM testing of Article 7 decisions. ${ }^{31}$

In the analysis of antitrust fines this general principle of proportionality can be translated into

\footnotetext{
${ }^{27}$ Tridimas, T., op.cit., p. 136.

${ }^{28}$ Schwarze (2006), European Administrative Law, p. 679.

${ }^{29}$ See Sauter (2013), p. 24.

${ }^{30}$ Council Regulation (EC) No 1/2003 of 16 December 2002 on the implementation of the rules on competition laid down in Article 81 and 82 of the Treaty, OJ 2003, LI/1.

${ }^{31}$ Case T-111/08, paras 323-324.
} 
"The fine should not be in excess of the lowest fine that suffices to prevent criminal cartel activity."

This translation is implemented in the model of the current paper.

In the US the application of principle of proportionality is less transparent. However, concepts of proportionality have long been an instrumental part of the rule of law. These concepts all embody the fundamental value that government and private actions should not be demonstrably excessive relative to their moral and practical justifications. Sullivan and Frase (2008) mention that the proportionality principle is quite frequently used in the American legal system, however, there is no general theory of what permits courts to invalidate excessive measures. Sullivan and Frase (2008) also examine the origins and the use of proportionality principles in the US and emphasize the importance of proportionality principles to guide the judicial review of excessive government measures.

\section{Appendix B: Optimal fine schedules when $\pi^{o p t}\left(p^{M}\right)>v^{*}$}

In Section 4, we mentioned technical issues related to the existence of the optimal fine schedule in case $\pi^{o p t}\left(p^{M}\right)>v^{*}$. This case corresponds to legal upper bounds that are relatively high so that $v^{*}$ is lower than $\pi^{o p t}\left(p^{M}\right)$. In this appendix we analyze this case in which the sustainability condition also plays a key role in the determination of the optimal fine schedule. We show that there are two intervals of cartel prices, one where the analysis of Section 4 still holds and one where a problem of existence of the optimal fine schedule arises.

By $\pi^{o p t}(\cdot)$ is increasing and $\pi^{o p t}\left(p^{M}\right)>v^{*}$, there exists a unique $\bar{p} \in\left[p^{*}, p^{M}\right)$ such that $\pi^{\text {opt }}(\bar{p})=v^{*}$. For all $p \in\left[p^{N}, \bar{p}\right],(12)$ once more simplifies to $\xi(p) \geq \frac{1}{\beta}\left[\pi(p)-(1-\delta) v^{*}\right]$ as in Section 4 and, therefore, the same arguments imply that the fine schedule given by (13) is the optimal fine schedule on this interval of prices. For $p \in\left(\bar{p}, p^{M}\right]$, however, (11) and (12) become

$$
v(p, \xi)<\pi^{o p t}(p) \Leftrightarrow \xi(p)>\frac{1}{\beta}\left[\pi(p)-(1-\delta) \pi^{o p t}(p)\right] .
$$


This implies that all prices $p \in\left(\bar{p}, p^{M}\right]$ are unsustainable as cartel prices. It is, however, impossible to weaken this strict inequality condition to a weak inequality. The reason for the strict inequality $v(p, \xi)<\pi^{o p t}(p)$ for $p \in\left(\bar{p}, p^{M}\right]$ is very different from the reason for the weak inequality $v(p, \xi) \leq v^{*}$ for $p \in[\hat{p}, \bar{p}]$. Recall that all $p \in[\hat{p}, \bar{p}]$ are sustainable and sustainability is not an issue because condition $v(p, \xi)=v^{*}$ ensures that the cartel would receive the minmax cartel profit even if the firms collude at price $p$. For any $p \in$ $\left(\bar{p}, p^{M}\right]$, however, equality instead of inequality in (18) would imply $v(p, \xi)=\pi^{o p t}(p)>v^{*}$. Consequently, the sustainable cartel price $p$ would be more profitable than $v^{*}$ and the minimal cartel price $\hat{p}$ could not be an optimal cartel price. Hence, any cartel price $p \in\left(\bar{p}, p^{M}\right]$ must be unsustainable and this requires strict inequality.

Condition (18) poses two issues in characterizing the optimal fine for $p \in\left(\bar{p}, p^{M}\right]$ and resolving these issues distracts attention from the fact that the antitrust authority can secure the minimal cartel price $\hat{p}$. The first issue is that the right-hand side of (18) need not be non-decreasing. Within our domain of monotone fine schedules, the optimal fine schedule is therefore bounded from below on the interval $\left(\bar{p}, p^{M}\right]$ by the monotone function $\eta$ that is the least monotone function that satisfies

$$
\eta(p) \geq \pi(p)-(1-\delta) \pi^{o p t}(p) \quad \text { for } \bar{p}<p \leq p^{M} .
$$

The function $\eta$ exists, it is bounded from below by the constant function $\pi(\bar{p})-(1-\delta) v^{*}$ and bounded from above by the monotone function $\pi(p)-(1-\delta) v^{*} \leq \beta \bar{\xi}(p)$. Obviously, equality in (19) holds in case the right-hand side is non-decreasing. Otherwise, there will be a strict inequality for some or all $p \in\left(\bar{p}, p^{M}\right]$.

If case (19) would hold with a strict inequality for all $p \in\left(\bar{p}, p^{M}\right]$, which holds whenever the right-hand side is decreasing in $p$, our analysis is done and the function $\eta$ characterizes the optimal fine schedule $\hat{\xi}$ for $p \in\left(\bar{p}, p^{M}\right]$. The optimal fine schedule is then given by

$$
\hat{\xi}(p)= \begin{cases}0, & \text { for } p^{N} \leq p \leq \hat{p} \\ \frac{1}{\beta}\left[\pi(p)-(1-\delta) v^{*}\right], & \text { for } \hat{p}<p \leq \bar{p} \\ \frac{1}{\beta} \eta(p), & \text { for } \bar{p}<p \leq p^{M}\end{cases}
$$


This fine schedule satisfies all legal principles and it implements the minimal cartel price $\hat{p}$ as the least optimal cartel price.

Unfortunately, the strict inequality in (19) may not hold for all $p \in\left(\bar{p}, p^{M}\right]$, which is the case in the classic Bertrand oligopoly for which $\pi^{o p t}(p)=n \pi(p)$, and this causes a second issue namely the least fine schedule $\eta$ fails as an optimal fine schedule on the interval $\left(\bar{p}, p^{M}\right]$. The consequence is that we cannot obey the principle of proportionality on $\left(\bar{p}, p^{M}\right]$. However, if we weaken this principle, the antitrust authority would be able to implement the minimal cartel price $\hat{p}$ as the least optimal cartel price within the domain of fine schedules that obey the other three legal principles. Note, however, that this issue is artificial. As is standard in many oligopoly models, we assume that money is perfectly divisible for technical convenience. In reality, there is a smallest money unit and one can break the equality $v(p, \xi)=\pi^{o p t}(p)$ by increasing $\xi$ by one smallest money unit. Here, the technical convenience of perfectly divisible money that served us well throughout the analysis turns against our main goal and we regard it as a technical matter of no practical importance.

Formally, consider the domain of monotone continuous fine schedules that satisfy both the lower and upper legal bounds. Within this domain, define the fine schedule $\hat{\eta}$ as a monotone continuous function on $\left(\bar{p}, p^{M}\right]$ such that $\lim _{p \rightarrow \bar{p}} \hat{\eta}(p)=\pi(\bar{p})-(1-\delta) v^{*}$ and $^{32}$

$$
\pi(p)-(1-\delta) \pi^{o p t}(p)<\hat{\eta}(p) \leq \pi(p)-(1-\delta) v^{*} \quad \text { for } \bar{p}<p \leq p^{M} .
$$

Then, $\hat{\eta}$ can replace $\eta$ in (20) and this modified fine schedule achieves the minimal cartel price $\hat{p}$ as the least optimal cartel price. Although $\hat{\eta}$ can approximate $\eta$ arbitrarily close, the strict inequality in (18) excludes that $\hat{\eta}$ coincides with $\eta$. So, we are able to satisfy three principles and by a hair the principle of proportionality on the interval $\left(\bar{p}, p^{M}\right]$.

Proposition 5 When $\pi^{\text {opt }}\left(p^{M}\right)>v^{*}>0$, the fine schedule given by

$$
\hat{\xi}(p)= \begin{cases}0, & \text { for } p^{N} \leq p \leq \hat{p}, \\ \frac{1}{\beta}\left[\pi(p)-(1-\delta) v^{*}\right], & \text { for } \hat{p}<p \leq \bar{p}, \\ \frac{1}{\beta} \hat{\eta}(p), & \text { for } \bar{p}<p \leq p^{M},\end{cases}
$$

\footnotetext{
${ }^{32}$ Many functions $\hat{\eta}$ exist, such as $\hat{\eta}(p)=\eta(p)+\beta \varepsilon(p-\bar{p})$ for small enough $\varepsilon>0$. Clearly, $\eta$ can be approximated arbitrarily close, but the principle of proportionality, i.e., $\varepsilon=0$, is ruled out.
} 
implements $\hat{p}$ as the least optimal cartel price, it satisfies the legal principles of punishment fits the crime, the legal lower bound and the legal upper bound. Moreover, it satisfies the legal principle of proportionality on $\left[p^{N}, \bar{p}\right]$.

Proof. First, notice that $\hat{\xi}(\cdot)$ by (20) is continuous and monotonic. For $p \in\left(p^{N}, \bar{p}\right]$, the proof is identical to the proof of Proposition 3, and every $p \in[\hat{p}, \bar{p}]$ can be sustained as a cartel price from which each firm earns the minmax cartel profit $v^{*}$. For $p \in\left(\bar{p}, p^{M}\right]$, $v(p, \hat{\xi})<\pi^{o p t}(p)$ implies that $p$ cannot be sustained as a cartel price. Therefore, the least optimal cartel price is equal to the minimal cartel price $\hat{p}$.

Although Proposition 5 does not pin down a unique optimal fine schedule, it provides a possible candidate for the optimal schedule in some special cases or if we weaken the legal principles. For example, if $\pi(p)-(1-\delta) \pi^{o p t}(p)$ is monotonically decreasing in $p$, then we can choose $\eta(p)$ to be the constant $\pi(\bar{p})-(1-\delta) \pi^{o p t}(\bar{p})=\pi(\bar{p})-(1-\delta) v^{*}$, and the corresponding $\hat{\xi}(\cdot)$ by $(20)$ is the optimal fine schedule. Recall from Section 4 that our insights relate to the results in Block, Nold, and Sidak (1981) by letting the optimal (differentiable) fine schedule solve the differential equation $\beta \xi^{\prime}(p)=\pi^{\prime}(p)$ for $p \in\left[\hat{p}, p^{M}\right]$ under the additional condition $\xi\left(p^{*}\right)=\bar{\xi}\left(p^{*}\right)$. This can also be done here and would result in the function $\hat{\eta}$ given by $\hat{\eta}(p)=\pi(p)-(1-\delta) v^{*}$ on the interval $\left(\bar{p}, p^{M}\right]$. Our analysis shows that such fine schedule achieves the minimal cartel price $\hat{p}$, but that it involves excessive fining.

The fine schedule (20) coincides with the optimal fine schedule given in (13) for all $p \in\left(p^{N}, \bar{p}\right]$ and the intuition discussed in Section 4 remains valid. Recall that all these cartel prices are sustainable. For $p \in\left(\bar{p}, p^{M}\right]$, the fine function $\frac{1}{\beta}\left[\pi(p)-(1-\delta) v^{*}\right]$ is still feasible and by its construction yields a profit of $v^{*}$ to each individual firm. Because $v^{*}<$ $\pi^{\text {opt }}(p)$ for all $p \in\left(\bar{p}, p^{M}\right]$, any price higher than $\bar{p}$ cannot be sustained if fine schedule $\frac{1}{\beta}\left[\pi(p)-(1-\delta) v^{*}\right]$ is imposed. However, it is possible to further lower the fine below $\frac{1}{\beta}\left[\pi(p)-(1-\delta) v^{*}\right]$ as long as these prices cannot be sustained as cartel prices. In other 
words, with any fine schedule such that

$$
\pi(p)-(1-\delta) \pi^{o p t}(p)<\beta \xi(p)<\pi(p)-(1-\delta) v^{*},
$$

each individual firm gets a profit that lies strictly between $v^{*}$ and $\pi^{o p t}(p)$. Because of the first inequality, the upper bound fails the principle of proportionality to deter cartel price $p$. Application of our insights to the boundary case $v^{*}=0$, which would violate condition (4), yields $\hat{p}=\bar{p}=p^{N}$ and $\frac{1}{\beta} \hat{\eta}(p)$ as the optimal fine schedule on $\left(p^{N}, p^{M}\right]$. For this boundary case, all issues discussed in this appendix hold.

To summarize, we regard the non-existence of the optimal fine schedule that satisfies all four legal principles on $\left[p^{N}, p^{M}\right]$ as a technical matter of no practical importance. However, independent whether this issue arises, the following conclusions hold. First, the antitrust authority can secure the minimal cartel price $\hat{p}$ by adopting the fine schedule given by (21). Second, such fine schedules satisfy all four legal principles on the interval $\left[p^{N}, \bar{p}\right]$.

\section{Appendix C: Optimal Antitrust Enforcement when $\bar{\beta} \leq$ 1}

In Section 5, we mentioned technical issues related to the existence of the optimal antitrust enforcement in case $\bar{\beta} \leq 1$. This case corresponds to legal upper bounds that are relatively high so that $\bar{\beta}$ in (16) is relatively low. In this appendix, we first show that it matters whether the supremum defining $\bar{\beta}$ in (16) is attained by a price in the range $\left(p^{N}, p^{M}\right]$, or that this supremum is only attained by the competitive price $p^{N}$. This imposes the necessity to distinguish these two cases and introduces the technical issue of existence of optimal antitrust enforcement. All technical issues are dealt with in this appendix.

Recall from Section 5 that full deterrence is obtained for $\beta>\bar{\beta}$, and only partial deterrence otherwise. Full deterrence is also obtained for $\beta=\bar{\beta}$ if the supremum in (16) is only attained at $p^{N}$. To see this, if the supremum would be attained at some price $p \in\left(p^{N}, p^{M}\right]$, then this price is a maximizer that satisfies (4) and, therefore, can be sustained as a cartel price allowing the cartel to make a positive profit under the legal upper bound. Obviously, 
this contradicts full deterrence. So, if the supremum in (16) is only attained at $p^{N}$ then the cartel profit must be zero. The following example demonstrates the necessity to distinguish two cases with respect to where the supremum defining $\bar{\beta}$ is attained.

Example 6 Consider the classic Bertrand oligopoly with $n$ firms, linear demand $2-p$ and constant marginal costs of 0 . Furthermore, suppose that the legal upper bound is given by $\bar{\xi}(p)=a+b p$, where $a, b \geq 0$. Then, $\pi^{\text {opt }}(p)=n \pi(p)$ and $\delta>(n-1) / n$ imply the supremum in (16) solves

$$
[1-n(1-\delta)] \sup _{p \in\left(p^{N}, p^{M}\right]} \frac{p(2-p)}{a+b p} .
$$

For a constant legal upper bound, i.e., $b=0$, the supremum is attained at $p^{M}=1$ and for $a$ linear legal upper bound with no intercept, i.e., $a=0$, the supremum is attained at $p^{N}=0$.

We continue with the easiest case: the supremum is only attained at $p^{N}$, or full deterrence at $\beta=\bar{\beta}$. Then for any $\beta \in[\bar{\beta}, 1]$, the competitive price $p^{N}$ is the only sustainable cartel price and the associated value function of (7) equals the present value of the profit under competition, which is 0 . If we express this present value as a function of $\beta$, we have $v^{*}(\beta)=0$. The optimal fine schedule $\hat{\xi}$ that implements the competitive price $p^{N}$ as the minimal cartel price and that satisfies the four legal principles is the function $\frac{1}{\beta} \hat{\eta}(p)$ for all $p \in\left(p^{N}, p^{M}\right]$, as discussed at the end of Appendix B.

For any $\beta \in[0, \bar{\beta})$, condition (4) holds and the cartel has some cartel price above the competitive price that is sustainable and it has an incentive to form. Then, it holds for the associated value function of (7) expressed as a function of $\beta$ that $v^{*}(\beta)>0$ on $[0, \bar{\beta})$ and $\hat{\xi}(p)$ given by either $(13)$ or $(21)$ implements $\hat{p}(\beta)$. We note that $v^{*}(\beta)$ is decreasing in $\beta$. Furthermore, recall that we defined $p^{*}$ as the optimal cartel price under the legal upper bound, as illustrated in Figure 1. For $\beta \in[0, \bar{\beta}]$, we define the set of all such maximizers as $P^{*}(\beta)$. Then, full deterrence at $\beta=\bar{\beta}$ must imply that $\lim _{\beta \uparrow \bar{\beta}} P^{*}(\beta)=\left\{p^{N}\right\}$, because otherwise we would obtain the contradiction that a sustainable cartel price above the competitive price exists at $\beta=\bar{\beta}$. Consequently, $\lim _{\beta \uparrow \bar{\beta}} v^{*}(\beta)=0$, and hence, the 
function $v^{*}(\beta)$ is continuous in $\beta$ on the entire interval $[0,1]$. Continuity of the function $v^{*}(\beta)$ is, similar to the proof of Proposition 4, the driving argument for existence of an optimal $\beta^{*} \in[0,1]$, which we do not further elaborate.

In case of full deterrence at $\beta=\bar{\beta}$, we can make a somewhat stronger statement. Recall that for all $\beta \in[\bar{\beta}, 1]$, we have that $\hat{p}(\beta)=p^{N}$ and, therefore,

$$
w(\hat{p}(\beta), \beta, \hat{\xi})=\frac{n \pi\left(p^{N}\right)+C S\left(p^{N}\right)-c(\beta)}{1-\delta} .
$$

This is a decreasing function of $\beta$. So, any $\beta>\bar{\beta}$ is suboptimal and we conclude that the optimal $\beta^{*}$ must lie in $[0, \bar{\beta}]$.

Similar as in Section 5, the structure of the optimal fine schedule in Section 4 has to be preserved in the setting where both the probability of detection and the fine schedule are endogenous. The above arguments and following the arguments of the proof of Proposition 4 imply the following result.

Proposition 7 Optimal antitrust enforcement $\left(\beta^{*}, \xi^{*}\right)$ has the following features:

(i) $\beta^{*} \in[0, \bar{\beta}]$ maximizes per-period social welfare $n \pi(\hat{p}(\beta))+C S(\hat{p}(\beta))-c(\beta)$ in order to implement the minimal cartel price $\hat{p}\left(\beta^{*}\right)$ and

(ii) $\xi^{*}(p)=\hat{\xi}\left(p, \beta^{*}\right)$, where $\hat{\xi}\left(p, \beta^{*}\right)$ is given by either (13), or (21).

In principle, this result is similar to Proposition 4 , except that $[0, \bar{\beta}]$ replaces $[0,1]$ and that full deterrence is attained at $\bar{\beta}$. Partial deterrence is optimal if $\beta^{*}<\bar{\beta}$ and, otherwise, full deterrence is optimal. In case of differentiability of all functions, (17) holds on $[0, \bar{\beta}]$ and a detection probability $\beta^{*}$ smaller than $\bar{\beta}$ requires that the marginal social benefits at the lowest full deterrence effort level $\bar{\beta}$ are lower than the marginal costs of that effort level, i.e., $\hat{p}^{\prime}(\bar{\beta})\left[n \pi^{\prime}(\hat{p}(\bar{\beta}))+C S^{\prime}(\hat{p}(\bar{\beta}))\right]<c^{\prime}(\bar{\beta})$.

The remaining case features partial deterrence at $\beta=\bar{\beta}$. In this case, the supremum in (16) is attained at some price $p \in\left(p^{N}, p^{M}\right]$, and then this price satisfies (4) and can be sustained as a cartel price allowing the cartel to make a profit $v^{*}(\bar{\beta})>0$. The function $v^{*}(\beta)$ is positive and continuous in $\beta$ on $[0, \bar{\beta}]$, and $v^{*}(\beta)=0$ for all $\beta \in(\bar{\beta}, 1]$. Moreover, 
even under the optimal fine schedule, the deadweight loss is positive for $\beta \in[0, \bar{\beta}]$ and zero for all $\beta \in(\bar{\beta}, 1]$. The social welfare $w(\hat{p}(\beta), \beta, \hat{\xi})$ is continuous on each of the intervals $[0, \bar{\beta}]$ and $(\bar{\beta}, 1]$. However,

$$
\lim _{\beta \uparrow \bar{\beta}} w(\hat{p}(\beta), \beta, \hat{\xi})=w(\hat{p}(\bar{\beta}), \bar{\beta}, \hat{\xi})<\lim _{\beta \downarrow \bar{\beta}} w(\hat{p}(\beta), \beta, \hat{\xi})=\frac{n \pi\left(p^{N}\right)+C S\left(p^{N}\right)-c(\bar{\beta})}{1-\delta} .
$$

So, social welfare $w(\hat{p}(\beta), \beta, \hat{\xi})$ makes an upward jump at $\beta=\bar{\beta}$. Furthermore, similar as before, $w(\hat{p}(\beta), \beta, \hat{\xi})=w\left(p^{N}, \beta, \hat{\xi}\right)$ is decreasing on $(\bar{\beta}, 1]$ and, therefore, every $\beta \in(\bar{\beta}, 1]$ is suboptimal. Note that

$$
\sup _{\beta \in(\bar{\beta}, 1]} w\left(p^{N}, \beta, \hat{\xi}\right)=\frac{n \pi\left(p^{N}\right)+C S\left(p^{N}\right)-c(\bar{\beta})}{1-\delta}
$$

is well defined and that, technically speaking, it cannot be attained. In practice, the supremum can be attained arbitrarily close.

To solve the remaining case, we split the optimization over $\beta$ into two separate optimizations over the intervals $[0, \bar{\beta}]$ and $(\bar{\beta}, 1]$ :

$$
\begin{aligned}
& w\left(p^{C}\left(\beta^{*}, \xi^{*}\right), \beta^{*}, \xi^{*}\right) \\
= & \sup _{\beta \in[0,1], \xi} w\left(p^{C}(\beta, \xi), \beta, \xi\right), \quad \text { s.t. } \xi \text { satisfies the four legal principles } \\
= & \sup _{\beta \in[0,1]}\left[\sup _{\xi} w\left(p^{C}(\beta, \xi), \beta, \xi\right)\right], \quad \text { s.t. } \xi \ldots \\
= & \max \left\{\sup _{\beta \in[0, \bar{\beta}]}\left[\sup _{\xi \text { s.t. } \xi \ldots} w\left(p^{C}(\beta, \xi), \beta, \xi\right)\right], \sup _{\beta \in(\bar{\beta}, 1]}\left[\sup _{\xi \text { s.t. } \xi \ldots} w\left(p^{N}, \beta, \xi\right)\right]\right\} .
\end{aligned}
$$

Obviously, the second term under the maximum is given by (24). Furthermore, the first term under the maximum can be solved similar as in Proposition 7:

$$
\frac{1}{1-\delta} \max _{\beta \in[0, \bar{\beta}]}[n \pi(\hat{p}(\beta))+C S(\hat{p}(\beta))-c(\beta)],
$$

where the minimal cartel price $\hat{p}(\beta)$ can be sustained by the optimal fine schedule of either (13), or (21). This optimization problem has similar properties as the one stated in Proposition 4. Let $\beta^{* *} \in[0, \bar{\beta}]$ be a maximizer of $n \pi(\hat{p}(\beta))+C S(\hat{p}(\beta))-c(\beta)$ on $[0, \bar{\beta}]$, which 
exists and is well-defined. Summarizing, (25) solves as

$$
\max \left\{\frac{n \pi\left(\hat{p}\left(\beta^{* *}\right)\right)+C S\left(\hat{p}\left(\beta^{* *}\right)\right)-c\left(\beta^{* *}\right)}{1-\delta}, \frac{n \pi\left(p^{N}\right)+C S\left(p^{N}\right)-c(\bar{\beta})}{1-\delta}\right\} .
$$

Hence, society prefers either to partially deter cartel formation by choosing its detection efforts to achieve $\beta^{* *} \in[0, \bar{\beta}]$, or to fully deter cartel formation by choosing its detection efforts slightly above $\bar{\beta}$. In the latter case, the non-existence of an optimal level of detection efforts should not be regarded as a real issue in practice. We omit summarizing all these results in a proposition.

To summarize Section 5 and this appendix, optimal antitrust enforcement $\left(\beta^{*}, \xi^{*}\right)$ maximizes per-period social welfare $n \pi(\hat{p}(\beta))+C S(\hat{p}(\beta))-c(\beta)$, implements the minimal cartel price $\hat{p}\left(\beta^{*}\right)$ and the optimal fine schedule derived in Section 4 has to be an integral part of optimal antitrust enforcement.

\section{References}

[1] Bageri, V., Y. Katsoulacos, and G. Spagnolo (2013) "The Distortive Effects of Antitrust Fines Based on Revenue," Bank of Greece, Discussion Paper number 153.

[2] Becker, G.S. (1968) "Crime and Punishment: An Economic Approach," Journal of Political Economy 76, 169-217.

[3] Besanko, D. and D. Spulber (1989) "Antitrust Enforcement under Asymmetric Information," The Economic Journal 99, 408-425.

[4] Block, M., F. Nold, and J. Sidak (1981) "The Deterrent Effect of Antitrust Enforcement," Journal of Political Economy 89, 429-445.

[5] Bos, I. and M.P. Schinkel (2006) "On the Scope for the European Commission's 2006 Fining Guidelines under the Legal Maximum Fine," Journal of Competition Law and Economics 2, 673-682. 
[6] Buccirossi, P. and G. Spagnolo (2007) "Optimal Fines in the Era of Whistleblowers Should Price Fixers Still Go to Prison?" in The Political Economy of Antitrust, by V. Goshal and J. Stennek (Eds.), Elsevier: Amsterdam.

[7] Burca, de, G. (1993) "The Principle of Proportionality and its Application in EC Law," 13 YEL 105.

[8] Connor, J.M. and R. H. Lande (2005) "How High Do Cartels Raise Prices: Implications for Optimal Cartel Fine," Tulane Law Review 80, 513- 570.

[9] Connor, J.M. and R.H. Lande (2006) "The Size of Cartel Overcharges: Implications for U.S. and EU fining Policies," Antitrust Bulletin 51, 983 -1022.

[10] Connor, J.M. and R.H. Lande (2008) "Cartel Overcharges and Optimal Cartel Fines", in S.Waller (ed), Issues in Competition Law and Policy, Vol 3, AMA Section of Antitrust Law, Chapter 88, 2203-2218.

[11] Connor, J.M. and R.H. Lande (2012) " Cartels As Rational Business Strategy: New Data Demonstrates that Crime Pays", mimeo.

[12] Cooter, R. and T. Ulen (2007) Law and Economics, Addison Wesley Longman.

[13] DOJ (2010) "US Sentencing Guidelines (Chapter 8: Sentencing of organizations)" http://www.ussc.gov/2009guid/CHAP8.htm

[14] EC (2006) "Guidelines on the Method of Setting Fines Imposed Pursuant to Article 23(2)(a) of Regulation no 1/2003," Official Journal of the European Union (2006/C 210/02), Brussels.

[15] Fabra, N. and M. Motta (2013) "Antitrust Fines in Times of Crisis", CEPR Discussion Paper No. DP9290

[16] Fish, M. (2008) "An Eye for an Eye: Proportionality as a Moral Principle of Punishment," Oxford Journal of Legal Studies 28, 57-71.

[17] Fudenberg, D. and J. Tirole (1991) Game Theory, MIT Press: Cambridge. 
[18] Garoupa, N. (1997) "The Theory of Optimal Law Enforcement," Journal of Economic Surveys 11, 267-295.

[19] Garoupa, N. (2001) "Optimal Magnitude and Probability of Fines," European Economic Review 45, 1765-1771.

[20] Harrington, J. (2004) "Cartel Pricing Dynamics in the Presence of an Antitrust Authority," The Rand Journal of Economics 35, 651-673.

[21] Harrington, J. (2005) "Optimal Cartel Pricing in the Presence of an Antitrust Authority," International Economic Review 46, 145-170.

[22] Harrington J. (2010) "Comment on Antitrust Sanctions," Competition Policy International 6, 41-51.

[23] Houba, H., E. Motchenkova, and Q. Wen (2012) "Competitive Prices as Optimal Cartel Prices," Economics Letters 114, 39-42.

[24] Immordino, G. and M. Polo (2013) "Antitrust, Legal Standards and Investment," IEFE Working Paper n. 54.

[25] Jacobs, F.G. (1999) "Recent Developments in the Principle of Proportionality in EC Law" in: Ellis, E., The Principle of Proportionality in the Laws in Europe, Hart Publishing, United Kingdom.

[26] Katsoulacos, Y. and D. Ulph (2013) "Antitrust Penalties and the Implications of Empirical Evidence on Cartel Overcharges", The Economic Journal, Forthcoming

[27] Landes, M. (1983) "Optimal Sanctions for Antitrust Violations," The University of Chicago Law Review 50, 652-678.

[28] Mookherjee, D. and I.P.L Png (1994) "Marginal Deterrence in Enforcement of Law," Journal of Political Economy 102, 1039-1066

[29] Motta, M. and M. Polo (2003) "Leniency Programs and Cartel Prosecution," International Journal of Industrial Organization 21, 347-379. 
[30] OECD (2002) "Fighting Hard-Core Cartels: Harm, Effective Sanctions and Leniency Programs" OECD Report 2002, OECD, Paris, France, http://www.SourceOECD.org.

[31] Polinsky, A. M. and S. Shavell (1979) "The Optimal Trade-Off between the Probability and Magnitude of Fines," American Economic Review 69, 880-891.

[32] Polinsky, A, M. and S. Shavell (1984) "The Optimal Use of Fines and Imprisonment," Journal of Public Economics 24, 89-99.

[33] Polinsky, A. M. and S. Shavell (1991) "A Note on Optimal Fines when Wealth Varies Among Individuals," American Economic Review 81, 618-621.

[34] Polinsky, A. M. and S. Shavell (1992) "Enforcement Costs and the Optimal Magnitude and Probability of Fines," Journal of Law and Economics 35, 133-148.

[35] Posner, R.A. (1976 \& 2001 second edition), Antitrust Law: An Economic Perspective, University of Chicago Press, Chicago

[36] Rey, P. (2003) "Towards a Theory of Competition Policy" in Advances in Economics and Econometrics: Theory and Applications by M. Dewatripont, L. Hansen, and S. Turnovsky, Eds., Cambridge University Press.

[37] Sauter, W. (2013) "Proportionality in EU law: a balancing act?," TILEC Discussion Paper No. 2013-003.

[38] Schwarze, J. (2006) "European Administrative Law", Office for Official publications of the European Communities.

[39] Shavell, S. (1992) "A Note on Marginal Deterrence," International Review of Law and Economics 12, 345-355.

[40] Shavell, S. (1993) "The optimal structure of law enforcement," Journal of Law and Economics 36, 255-287. 
[41] Stigler, G. (1970) "The Optimum Enforcement of Laws," Journal of Political Economy 78, 526-536.

[42] Souam, S. (2001) "Optimal Antitrust Policy under Different Regimes of Fines," International Journal of Industrial Organization 19, 1-26.

[43] Sullivan, E. and R.S. Frase (2008) "Proportionality Principles in American Law: Controlling Excessive Government Actions", Oxford University Press.

[44] Tridimas, T. (2006) "The General Principles of EC Law," Oxford EC Law Library, Oxford University Press.

[45] Usher, J.A. (1998) "General Principles of EC Law," European Law Series, Longman.

[46] Werden, G. and M. Simon (1987) "Why Price Fixers Should Go to Prison," The Antitrust Bulletin 32, 917-937.

[47] Wilde, L. (1992) "Criminal Choice, Nonmonetary Sanctions, and Marginal Deterrence: A Normative Analysis," International Review of Law and Economics 12, 333-44.

[48] Wils, W. (2007) "The European Commission's 2006 Guidelines on Antitrust Fines: A Legal and Economic Analysis" in World Competition 30. 